\title{
¿Para qué filosofar? Funciones de la filosofía
}

En la época contemporánea, caracterizada por el pragmatismo más tenaz y la visión tecnocrática del desarrollo social, en ocasiones parece prevalecer el criterio de que dedicarse al estudio de la filosofía no constituye más que una pérdida de tiempo.

Algunos consideran que ya pasó el momento en que se estudiaba filosofía y letras sólo para portar el anillo de graduado e impresionar al visitante con el majestuoso pergamino ostentador en la pared de dicho título, aunque la actividad del nombrado finalmente no tuviese mucho que ver con las pretensiones académicas de tal documento.

En el mundo actual saturado de tantas profesiones que a diario pierden su valor por los golpes que le propugna la aceleración tecnológica, en tiempos de globalización presuntamente posmoderna (Guadarrama, 2006), nada tiene de extraño que la dedicación exclusiva a la filosofía sea vista por algunos casi como una extravagancia, o la forma más refinada de ser toda la vida un "muerto de hambre“. Por lo que sólo es admisible tal dedicación si está acompañada de una sustentación financiera a través de las más exitosas vías extrafilosóficas.

Lo peor es que este común criterio de la conciencia cotidiana se ha trasladado, con la valoración de dicha actividad, a otras épocas y se llega a pensar 
injustamente que toda la vida los filósofos no han constituido más que un reducido círculo de ociosa carga social, que junto a poetas, artistas, entre otros, no han producido más que preocupaciones por seudoproblemas.

Afortunadamente no ha sido siempre este el criterio que ha prevalecido. Ha sido más común que, desde que la filosofía se constituyó en actividad intelectual específica, sus practicantes gozaran de un prestigio especial al considerárseles no sólo sabios, sino personas a las cuales se les debía escuchar o leer a fin de orientar mejor la actitud ante los problemas más trascendentales como la vida, la muerte, Dios, la felicidad, el conocimiento, entre otros.

Esto significa que alguna utilidad se apreció en el cultivo de dicha profesión. De otro modo no se explica la alta estimación que filósofos recibieron en muchas cortes y otros círculos de poder, y que en el presente se les aprecie y hasta contrate, como el caso de los think tanks. ${ }^{1}$

Con el nacimiento de la modernidad la filosofía fue ampliando su radio de productores y consumidores. Sin embargo, por esa misma razón, un mayor número de personas han tenido acceso a un nivel cultural más elevado y han podido plantearse la sempiterna pregunta ¿para qué sirve la filosofía?

En ocasión anterior abordamos el asunto del por qué y para qué filosofar en la perspectiva de la producción filosófica que se observa en América Latina, en la cual apreciamos al menos tres tendencias principales: hermenéutica, latinoamericanista y dialéctico-materialista (Guadarrama, 1989). Cada una de ella presupone una visión muy distinta del objeto y el sujeto del filosofar en correspondencia con los criterios manejados respecto a lo universal en la cultura (Guadarrama, 1989).

Los filósofos en las distintas épocas se han pronunciado de un modo u otro ante esta pregunta, aunque no haya constituido éste de forma especial un tema particular de mayor atención, pues como plantea Bueno (1995) "La consideración del papel de la filosofía no es una cuestión perifilosófica sino que nos introduce en el centro mismo de los problemas de la filosofía, los problemas en torno a la naturaleza del saber“ (p. 82).

1 Los llamados tanques pensantes (think tanks) son una evidente muestra de que los filósofos han adquirido en la actualidad cierta reputación en determinadas esferas como consultores de algunas instituciones de ciertos aparatos estatales. No es de extrañar en ocasiones se les contrate al igual que astrólogos, magos, hechiceros, entre otros, y otros supuestos poseedores de poderes esotéricos. 
En la actualidad se está en mejores condiciones de hacer un balance reconstructor del papel de la filosofía, pues se tienen muchos más elementos de la producción cultural de distintos pueblos que filósofos e historiadores de épocas anteriores quienes no siempre contaron con dichas fuentes. Pero ese análisis se ejecuta no con intenciones eruditas sino prospectivas a fin de decidir si vale la pena o no seguir cultivando este tipo de saber, independientemente del hecho de que los seres humanos del futuro tendrán sus razones para hacerse la misma pregunta: ¿para qué filosofar?.

A la filosofía se le pueden atribuir múltiples funciones que explican por qué tantos pensadores en distintas épocas y circunstancias se han dedicado a su cultivo. Entre ellas se pueden destacar las siguientes con sus consecuentes objetivos:

\begin{tabular}{|c|c|}
\hline Función & Objetivos \\
\hline 1. Cosmovisiva & Saber, comprender, pronosticar. \\
\hline 2. Lógico-metodológica & Examinar, criticar, enjuiciar, analizar. \\
\hline 3. Axiológica-hermenéutica & Valorar, interpretar, apreciar. \\
\hline 4. Hegemónica & Dominar, controlar, cooptar. \\
\hline 5. Práctico-educativa & Transformar, cultivar, superar. \\
\hline 6. Emancipadora & Liberar, emancipar, desalienar. \\
\hline 7. Ética & Comportar, reconocer, conducir. \\
\hline 8. Político-ideológica & Orientar, disponer, manipular, convocar. \\
\hline 9. Estética & Disfrutar, deleitar, gustar, estimular. \\
\hline 10. Humanista & Perfeccionar, progresar, humanizar. \\
\hline
\end{tabular}

Fuente: elaboración propia.

La primera de ellas, la función cosmovisiva ha sido una de las que más distinguió a la filosofía desde sus primeras manifestaciones hasta nuestros días.

La filosofía surgió como saber diferenciado en el proceso emancipador de la conciencia mítico-religiosa, en su delimitación paulatina del conocimiento empírico y científico, y en su diferenciación de las restantes formas de la conciencia social.

También se diferenció radicalmente de la conciencia cotidiana de los pueblos por sus marcadas pretensiones abstractas de conformación de un cuerpo teórico de ideas nucleicas sobre bases racionales que posibilitan contribuir al cultivo del saber sobre el comportamiento de los fenómenos tanto del mundo natural, como social y de la psiquis humana, a fin de contribuir 
a comprender y pronosticar su desenvolvimiento. Ella se constituye en paradigma supremo de referencia para la reflexión y la acción de los seres humanos en circunstancias históricas de madurez en cuanto al desarrollo social y su proceso de diferenciación.

Algunos de los pueblos del Oriente Antiguo alcanzaron también un nivel de desarrollo tanto en el orden material como espiritual que permitieron asegurar la existencia propiamente de filosofías en esas culturas, aunque el término posea una exclusiva procedencia griega y hoy aparezcan incluso como forzadas algunas traducciones a las lenguas modernas del concepto cuyo contenido se corresponde a este tipo de saber en las lenguas orientales.

Hasta los primeros historiadores de la filosofía como Diógenes Laercio planteaban - aunque aun hoy en día no se acepte generalmente- que la filosofía había tenido su origen en lo que los griegos denominaban pueblos bárbaros. Al respecto planteaba "Dicen algunos que la Filosofía excepto el nombre, tuvo su origen entre los bárbaros; pues como dice Aristóteles en su Mágico, y Soción en su libro XXIII De las Sucesiones, fueron los magos sus inventores entre los persas; los caldeos entre los sirios y babilonios; los gimnosofistas entre los indios; y entre los celtas y galos los druidas, con los llamados Semnoteos" (Laercio, 1990, p. 9).

En la actualidad las investigaciones confirman el criterio de que la gestación de las ideas filosóficas no fue un producto exclusivo de los griegos, aunque indudablemente en ese pueblo la filosofía logró un status, desarrollo, proliferación y prestigio anteriormente desconocidos.

Tanto en la China, como en la India prevaleció la concepción de lo que posteriormente se denominaría filosofía como un tipo de saber que aspiraba a profundizar en las vías esenciales que permiten el mejor conocimiento del mundo.

En los Upanischadas ese antiguo documento de la India sostenía Vivekachudamani, entre otros filósofos, que "Vano es el estudio de la filosofía si no conduce al conocimiento de la esencia" (Miscellaneous, 1944, p. 58). En tanto que Yogavasishtha por su parte planteaba que "El hombre liberado piensa siempre en el Ser, que es la meta de todo razonamiento filosófico, el conocimiento de todo corazón, que es el todo y está por doquiera"(Miscellaneous, 1944, p. 126) (la itálica fuera del texto original). Esta búsqueda de las determinaciones del Ser sobre bases eminentemente lógicas 
que ya se diferenciaban de cualquier deidad, constituían el salvoconducto principal para la entrada en el reino de la filosofía.

Similar interés por la totalidad está presente en otras concepciones filosóficas como el taoísmo. Según Granet, "Las ideas conjuntas de Orden, de Total, de Eficacia dominan el pensamiento de los chinos. No se han preocupado de descubrir reinos en la Naturaleza. Toda realidad es en sí total. Todo en el Universo es como el Universo" (Granet, 1959, p. 23). Sin embargo, la intención omnicomprensiva de los orientales no estaba dirigida a la simple erudición sino que está articulada a la función práctica del saber filosófico en cuanto instrumento eficaz para lograr una vida más útil y feliz.

En el mundo griego alcanzó una mayor plenitud el criterio de que el filósofo es aquel que "ama la sabiduría, no en parte, sino en su totalidad" (Platón, 1968, p. 372), como sostenía Platón. Ese criterio seguiría marcando la especificidad del saber filosófico para todos los tiempos.

Por su parte, Aristóteles concebía a la filosofía como una ciencia, pero con la particularidad de que "no se identifica con ninguna de las que hablan parcialmente del ser, porque ninguna de las demás ciencias se ocupa del ser como ser, con su universalidad" (Aristóteles, 1968, p. 95). Tal visión totalizadora que implica despojar al ser de sus determinaciones particulares se constituyó en característica fundamental del saber filosófico. En la antigüedad el conocimiento científico no era suficiente para penetrar en las esferas específicas de la realidad y en su lugar la filosofía intentaba abordarla en su totalidad.

Algunos podrán cuestionarse en qué medida resulta funcional un tipo de conocimiento tan genérico. Precisamente su mayor utilidad radica en que posibilita una orientación de actitudes desde una perspectiva más amplia que las que pueden ofrecer otras formas del conocimiento humano. Por tal razón, el hombre puede tomar en consideración elementos muy distintos por su nivel de generalización y abstracción a los empleados cuando efectúa su análisis desde una parcela más estrecha del saber o desde otra perspectiva como el caso de la religiosa.

Esto presupone que la filosofía por sí misma tampoco puede lograr todo el conocimiento a que aspira el ser humano. Para ello es necesario que se apoye en los resultados de las ciencias y en toda la experiencia humana sistematizada.

Uno de los momentos de mayor utilidad gnoseológica de la filosofía fue cuando predominó sobre las restantes formas de la conciencia social, como en el caso del mundo griego. Allí su intención omnicomprensiva desplegó hasta 
el máximo posible para la época sus potencialidades y pudo irradiar esclarecedoramente sobre los incipientes conocimientos científicos, la política, la moral, el arte, el derecho y hasta sobre la religión, aun cuando esta última no cesase en su empeño permanente de permearla, como no renunciará jamás.

La pragmática utilización que de la filosofía se hizo en la cultura romana puso de manifiesto que sus distintas funciones no siempre se mantienen equilibradas o en igual proporción. Por el contrario, aunque subsistan de algún modo en épocas y regiones diferentes, unas funciones toman mayor fuerza en correspondencia con las exigencias circunstanciales.

Durante la Edad Media, la función omnicomprensiva de la filosofía quedó limitada y subordinada al poder de la religión, que se autoconstituyó en saber absoluto dominante y no posibilitaba autonomía a los elementales conocimientos científicos existentes, ni a la filosofía y mucho menos al pensamiento político y jurídico.

No había forma del pensamiento que escapara a su tutela. Tal subordinación quedó refrendada en San Buenaventura, para quien "todo conocimiento viene subordinado y sirve a la teología, ciencia de Dios, por lo cual toma ejemplos y usa términos de todo género de conocimientos" (Buenaventura, 1975, p. 510), como en Tomás de Aquino quien dejó muy poco margen de libertad en cuanto a la delimitación del objeto de la filosofía al plantear que "las reflexiones de casi toda la filosofía se ordenan al conocimiento de Dios" (Aquino, 1975, p. 322).

Una vez más se le planteó al saber filosófico la tarea de emanciparse de la tutela religiosa para poder desarrollar plenamente su función cosmovisiva. Siempre que la filosofía hace algún tipo de concesión en cuanto a su objeto de estudio y los métodos racionales para estudiarlo, pierde parte de su poderío y autonomía.

En la medida en que el Renacimiento orientó más su preocupación hacia la problemática antropológica en lugar de la teológica, y fue rompiendo las ataduras de la escolástica, como se apreció en Erasmo, la misión cosmovisiva de la filosofía pudo ser apreciada de manera más evidente y específica.

Con la modernidad, la filosofía incrementó sus pretensiones sistematizadoras del conocimiento de la realidad. Se articuló cada vez más con la función lógico-metodológica, que aunque ya estaba plenamente enunciada desde la antigüedad, adquiriría un perfil más declarado, especialmente a través de lo que se conoce como la confrontación entre el racionalismo y el empirismo. 
La superación de ambas posiciones intentó alcanzar la filosofía de la ilustración y en especial la filosofía clásica alemana a partir de Kant, quien para elaborar su suigéneris gnoseología partió del presupuesto omnicomprensivo de que "si es verdad que todos nuestros conocimientos comienzan con la experiencia, todos sin embargo no proceden de ella" (Kant, 1973, p. 33). De tal modo insistía en el papel activo y decisivo del sujeto en el proceso cognoscitivo, que hasta Marx fue más desarrollado generalmente por el idealismo filosófico.

En Hegel, la filosofía llegó a la consumación de su pretensión cosmovisiva con la elaboración de sistemas que pretendieron abordar todas las esferas posibles del conocimiento humano. Para el pensador alemán "su contenido no es otro que el que originariamente se ha producido y produce en el dominio del espíritu viviente en el mundo exterior e interior de la conciencia, esto es, que su contenido es la realidad" (Hegel, 1968, p. 22). Pero la realidad en su conjunto es como una totalidad que exige ser interpretada conceptualmente y la formas suprema de tal interpretación es lógicamente la filosofía.

La filosofía clásica alemana le rindió culto a la filosofía como forma superior del saber humano, de ahí que cada uno de sus representantes trató a su modo de construir un sistema abarcador de todo el conocimiento humano. No era otra la intención de Fichte con su Teoría de la ciencia o de Schelling con sus Sistema del idealismo trascendental.

Sin embargo sería un filósofo de menor reconocimiento por la historiografía filosófica, Feuerbach, quien daría las claves desde la perspectiva del materialismo para demostrar las debilidades de los grandes sistemas filosóficos idealistas y especulativos, sin que esto significase el abandono de la función cosmovisiva de la filosofía.

A su juicio, "La filosofía es el conocimiento de lo que es. La ley suprema de la filosofía, su más alta misión, consiste en pensar y conocer las cosas y seres tal y como ellos son. Lo que es tal como es, por tanto, lo verdadero expresado verdaderamente, parece superficial; lo que tal como no es, por tanto, lo verdadero expresado no verdaderamente e invertidamente, parece ser profundo" (Feuerbach, 1985, p. 60). La validez de esta tesis se comprueba fácilmente cuando se está en presencia de algunos de esos oscuros y esotéricos sistemas filosóficos que impresionan al lector desviando su atención de las más sencillas verdades.

En la antigüedad el intento omnicomprensivo de la filosofía quedó plasmado en lo que se consideró sus tres partes fundamentales: física, lógica y 
ética. Posteriormente esta división no fue suficiente para determinar su verdadero radio de acción y nuevas complejas subdivisiones se incorporarían de forma cada vez más especializada, como filosofía de la historia, del derecho, del arte, de la religión, entre otras. Se trataba de dejar bien establecido que no existe porción alguna de la realidad que pueda escapar a su mirada escrutadora y su intención de comprender todos los fenómenos del infinito universo.

Esa pretensión abarcadora y predictiva se mantiene presente en la filosofía contemporánea, aun cuando sea de un modo diferente, pues algunas, aunque hayan rechazado explícitamente el criterio de considerar a la filosofía como una ciencia de las ciencias, no han renunciado a que su escalpelo metodológico descubra los misterios entrañables de nuevas esferas de la realidad y por tanto del conocimiento antes ignoradas por el ser humano.

Así, aunque la postura de Marx y Engels era crítica frente a los sistemas filosóficos absolutos y cerrados, porque consideraban que "el sistema es, cabalmente, lo efímero en todos los filósofos” (Marx, Engels, 1955, pp. 384-385), ${ }^{2}$ sin embargo algunos de sus seguidores en nombre del marxismo $^{3}$ (Guadarrama, 2013, pp. 225-227) le construyeron con el materialismo dialéctico un aparato tan especulativo como aquellos sistemas inamovibles que aquél había criticado, sin que esto significase renunciar a la necesaria sistematización del saber que demanda toda filosofía.

2 “(...), y lo es precisamente porque brota de una necesidad imperecedera del espíritu humano: la necesidad de superar todas las contradicciones. Pero superadas todas las contradicciones de una vez y para siempre, hemos llegado a la llamada verdad absoluta, la historia del mundo se ha terminado, y, sin embargo, tiene que seguir existiendo, aunque ya no tenga nada que hacer lo que representa como se ve, una nueva e insoluble contradicción. Tan pronto como descubrimos -y en fin de cuentas nadie nos ha ayudado más que Hegel a descubrirlo- que planteada a así la tarea de la filosofía, no significa otra cosa que pretender que un solo filósofo nos de lo que sólo puede darnos la humanidad entera en su trayectoria de progreso; tan pronto como descubrimos esto, se acaba toda filosofía, en el sentido tradicional de esta palabra. La 'verdad absoluta', imposible de alcanzar por este camino e inasequible para un solo individuo, ya no interesa, y lo que se persigue son las verdades relativas, asequibles por el camino de las ciencias positivas y de la generalización de sus resultados mediante el pensamiento dialéctico." Engels, Federico. "Ludwig Feuerbach y el fin de la filosofía clásica alemana". Marx, C. y F. Engels. Obras Escogidas. Ediciones en Lenguas Extranjeras. Moscú. 1955. pp.384-385.

3 "Es conocido que Marx en una entrevista para un diario en inglés a la pregunta si él era marxista, respondió en francés que precisamente él no era marxista. 
Muchos críticos del socialismo y del marxismo utilizan esta expresión de Marx para desprestigiarlo y presentarlo como alguien retractado o avergonzado de lo que había pensado o propuesto.

En verdad no hay nada más alejado de la verdad que tal tergiversación. Pues, jamás Marx se retractó de sus extraordinarios descubrimientos científicos y mucho menos de su postura revolucionaria, crítica del capitalismo y propugnadora del ideario socialista y comunista orientado hacia la gestación de una sociedad más equitativa y humana.

Todo parece indicar que su respuesta en francés se debió a que le interesaba que esta se divulgara bien en Francia, donde se había propagado la denominación de marxista para aquellos que, como su yerno el cubano Pablo Lafargue, se presentaban a sí mismos como los "marxistas" o discípulos de Marx, quien según ellos había descubierto todas las leyes universales de la historia.

Ante tal exageración, Marx con justificada modestia, argumentaría que él no había realizado un descubrimiento de semejante envergadura, sino que su contribución se limitaba a la determinación del mecanismo económico de la moderna sociedad capitalista especialmente en Europa Occidental, como también le argumentaría en otra a un historiador ruso. A este último le recalcaría que aquellos que le atribuían que él había descubierto todas las leyes de la historia universal le hacían demasiado honor, pero también daño.

Sería en parte también Engels el que planteó que la doctrina debía llevar el nombre de marxismo. Engels se consideraba a sí mismo solamente como un hombre de talento que le había tocado desempeñar el papel de segundo violín, pues a su juicio, Marx era un genio y sus dos descubrimientos esenciales la plusvalía y la concepción materialista de la historia eran razón suficiente para afirmar con razón que "Su nombre vivirá a través de los siglos, y con él su obra". A la vez Engels apuntaba que "Marx era el hombre más odiado y más calumniado de su tiempo", pero inmediatamente destacaba que "... si pudo tener muchos adversarios, apenas tuvo un solo enemigo personal".

En realidad, debe siempre destacarse la extraordinaria labor de Engels en orientar a Marx hacia los estudios de la economía política cuando este último en su juventud dedicaba mayor atención a temas filosóficos de carácter antropológico. Nadie debe dudar el valor y la significación filosófica del pensamiento de Engels independientemente de algunas simplificaciones

Lo cierto es que el término de marxismo quedó reconocido y divulgado ya en la misma época en que Marx vivía a pesar de su desacuerdo con él. Algo similar parece que ocurrió con el de leninismo que el propio Lenin nunca admitió. Entonces, ¿de dónde surgiría el denominado marxismo-leninismo? Este se formula después de la muerte de Lenin, con el auspicio de Stalin, quien, dado su extraordinario culto a la personalidad, propició de inmediato que se creara el Instituto de MarxismoLeninismo-Stalinismo, propiciador del materialismo dialéctico -incorrectamente atribuido a la creación de Marx y Engels- con sus nefastas consecuencias, no solo para la filosofía sino para la concepción y la práctica del primer ensayo de construcción del socialismo en el mundo.

Debe tenerse presente que si bien en la antigüedad y hasta inicios de la modernidad fue común utilizar el nombres de filósofos para denominar algunas relevantes 
El positivismo de Comte y Spencer, que sufrió una metamorfosis suigéneris en el ámbito latinoamericano (Guadarrama, 2004), no obstante su oposición

posturas filosóficas como el platonismo, aristotelismo, tomismo, kantismo, hegelianismo, etc., ya en la época de Marx y Engels comenzaba a ponerse fin a esa tendencia, por lo que no ha sido común que surgiesen posteriormente denominaciones tales como deweyismo, nietzschenismo, husserlianismo, russellianismo o heidegerianismo en lugar de como se conocen las respectivas concepciones de filósofos como Dewey, Nietzsche, Husserl, Russell o Heidegger, esto es, pragmatismo, vitalismo, fenomenología, neopositivismo o existencialismo.

Parece que la filosofía es cada vez más reacia tanto a los patronímicos como a los gentilicios, por lo que no existe propiamente ninguna que haya tenido un exclusivo origen endógeno, o sea dentro de las exclusivas fronteras de un pueblo sin nutrirse de los aportes del pensamiento de otros, como en ocasiones han pretendido algunos hiperbolizadores de los aportes de la cultura occidental. Por eso Aristóteles, reconoció el aporte de los egipcios y los gimnosofistas de la antigua India como le comunicó a Alejandro Magno, del mismo modo que Diógenes Laercio reconoció la existencia de filosofía mucho antes que los griegos en los pueblos del Medio Oriente y su influencia sobre la cultura helénica.

Si eso sucedió en la Antigüedad, cuando los intercambios culturales eran mucho más limitados, mucho menos se puede admitir a partir de la modernidad autarquías filosóficas y nacionalismo estrechos que lleven a aceptar como propiamente válidos los términos de filosofía alemana, inglesa, francesa, española, etc., ignorando las recíprocas influencias de pensadores de unos países sobre otros. Del mismo modo resulta algo cuestionable admitir la existencia de una filosofía cubana, colombiana, venezolana o latinoamericana, en lugar de reconocer la existencia de producción filosófica en Cuba, Colombia, Venezuela o Latinoamérica del mismo modo que en Alemania, Inglaterra, Francia, España o Europa.

El marxismo, -entendiéndose bajo este término tanto una filosofía como una teoría económica, sociológica, política de extrovertida o culpable confesión ideológica ha constituido una síntesis teórica de una época y como salto cualitativo superador del pensamiento filosófico anterior de la humanidad que ha continuado desarrollándose con éxitos y fracasos, aciertos y errores por discípulos y seguidores de aquellos no solo en Europa sino en otras regiones del orbe, como en África.

Es imposible analizar la historia de esta concepción ignorando a intelectuales y a dirigentes revolucionarios como Joseph Dietzgen, Pablo Lafargue, Jorge Plejanov, Vladimir Ilich Lenin, Rosa Luxemburgo, León Trotsky, Georgy Lukács, Antonio Gramsci, Louis Althusser, etc. Del mismo modo que fuera del contexto europeo a Mao Tse Tung, Ho Chi Minh, Almírcal Cabral, José Carlos Mariátegui, Ernesto Guevara, Fidel Castro, Antonio García Nosa, Rodney Arismendy, Adolfo Sánchez Vázquez, etc. Pero también sería poco honesto pensar que todos desarrollaron de manera similar la teoría marxista o que esta no ha tenido tropiezos, obstáculos que salvar, momentos de retrasos, de dogmatismos, de anquilosamiento". Guadarrama, P. Pensamiento Filosófico Latinoamericano. Humanismo, método e historia. Universitá degli Studi di Salerno-Universidad Católica de Colombia-Planeta. Bogotá. Tomo III. 2013. pp. 225-227. 
a la metafísica tradicional, no escapó a la construcción de sistemas filosóficos tan abarcadores que intentaban clasificar todo el conocimiento científico, los "estadios" de la evolución de la humanidad, los "primeros principios" sobre los que se rige todo lo existente. Según Comte "la verdadera filosofía se propone sistematizar, en la medida de lo posible, toda la experiencia humana, individual y sobre todo colectiva, contemplada a un tiempo en los tres órdenes de fenómenos que la caracterizan, pensamientos, sentimientos y actos" (Comte, 1973, p. 271) (itálica fuera del texto original). Los discípulos de esa corriente no han renunciado a la explicación de todo lo existente, solo que lo han intentado a través del prisma de alguna ciencia en distintos momentos como la biología, la psicología, la física, la lingüística, y otras.

En el panorama contemporáneo de la filosofía cada una de las nuevas corrientes de pensamiento que han ido apareciendo han expresado siempre, de algún modo, aunque por vías diferentes, esa aspiración cosmovisiva del saber filosófico, aun cuando no se revela necesariamente en la construcción de un sistema articulado para ese fin.

Pero no es difícil descubrir en Nietzsche, en Husserl, Sartre, Heidegger, Ortega o Vasconcelos y otros pensadores latinoamericanos elementos que atestiguan tal intención, de la misma forma que se aprecia en Habermas o Appel a través de la "acción comunicativa". Para aquel filósofo mexicano, caracterizado por ser uno de los que más pretendió en esta región conformar un sistema filosófico omnicomprensivo, el del monismo estético, el problema de la filosofía contemporánea, más complicado que el de cualquier época anterior, consiste en descubrir sistemas de unidad, sin eliminación de factores, unidad sustancial por encima de la disparidad formal y de la diferencia de estados dinámicos. Además un rumbo hacia el cual converjan todas las direcciones dispersas (Vasconcelos, 1929, p. 161).

Constantemente afloran nuevas manifestaciones de esa intención cosmovisiva de la filosofía. El día que se abandone tal empresa habrá muerto la filosofía y ya no tendrá sentido hacerse la pregunta ¿para qué filosofar?, porque el ser humano de forma ilusa pensará que ya posee todas las respuestas posibles a los constantes enigmas del mundo.

Algo similar ocurre con la función lógico-metodológica que posibilita el ejercicio del examen detallado y el enjuiciamiento crítico que siempre debe conllevar el más genuino análisis filosófico. 
Desde la antigüedad quedó establecido que la filosofía constituía ante todo un camino acertado para el logro de la sabiduría. Para Séneca es "la sabiduría de la perfección del alma humana. La filosofía es el amor y la investigación de la sabiduría" (Séneca, 1963, p. 192). Tal diferencia entre filosofía y sabiduría fue importante en el mundo grecolatino desde los primeros que comenzaron a emplear la palabra filosofía como Pitágoras y Heráclito. Para ellos estaba adecuadamente concebida la misión epistemológica de la filosofía en la conformación de una sabiduría (sophia) mucho más efectiva que la simple erudición.

En Parménides esa función se expresaba en que el objetivo de la filosofía consiste en contraponer la verdad y la apariencia (Abbagnano, 1967, T.I, p. 28), para lo cual se requiere un acertado empleo de la lógica.

Sin un escrupuloso manejo de los conceptos era imposible para Sócrates el logro del verdadero conocimiento, por eso Aristóteles reconocía que: “dos cosas son, efectivamente, las que hay que atribuir a Sócrates por propio derecho: el principio de la inducción y el de la definición de valor universal. Ambas cosas son el principio de toda ciencia" (Aristóteles, 1968, p. 323). Tal criterio quedó grabado en su discípulo por excelencia, Platón quien consideraba que "los filósofos son los que perciben lo que mantiene su identidad consigo mismo" (Platón, 1946, p. 387), tarea para la cual deben estar armados de la lógica más efectiva, como lo hizo Aristóteles en su Órganon al sintetizar los alcances de la lógica hasta su época y llevarla a un plano superior a partir del criterio: saber es demostrar.

Más allá de la utilización intencionada de que fue objeto la lógica deductiva aristotélica por parte de la escolástica a fin de ponerla a servicio de la teología, lo cual indica a su vez para qué puede servir también la filosofía. La lógica aristotélica perdurará por el rico arsenal epistemológico que encierra, a pesar de sus limitaciones que ya desde el Renacimiento comenzaron a ser criticadas.

En esa labor se destacó Francis Bacon al enfrentarse al deductivismo aristotélico predominante hasta entonces (Bacon, 1963, p. 848). ${ }^{4}$ La modernidad

4 "Dos son, y no más, los caminos a través de los cuales se puede buscar y encontrar la verdad: el uno arrancando de la sensación y de las cosas particulares, elevase inmediatamente a los axiomas (Principios) más generales, y luego partiendo de estos mismos principios y de su inconmovible verdad, descubre los axiomas intermedios; 
burguesa exigía una aceleración de los conocimientos científicos que posibilitaran avances en la industria, la navegación y otras formas de comunicación. Los avances en los métodos lógicos de obtención del conocimiento posibilitarían salir del marasmo de la autarquía feudal y abrir el mundo a un necesario y mejor autoconocimiento.

La función lógico-metodológica de la filosofía se articularía mucho más a la hegemónica, pues se trataba de proporcionarle al ser humano las armas conceptuales que le permitirían ejercer su dominio no sólo sobre la naturaleza, sino sobre la sociedad, y el control sobre sí mismo.

El objeto de la lógica fue alcanzando un mayor grado de concreción y utilidad hasta el punto de revelar las infinitas posibilidades de la actual cibernetización del mundo contemporáneo.

Ese carácter concreto de la reflexión lógica fue muy apreciado por Hegel, a quien se le considera un filósofo muy abstracto. Pero precisamente por haber hecho un uso adecuado de la abstracción comprendió el contenido concreto que exige una formulación filosófica que se fundamenta en una acertada formulación de la lógica. Según él, "es inapropiado decir que la lógica hace abstracción de cualquier contenido, que enseña sólo las reglas del pensar, sin penetrar en lo que ha sido pensado, y sin poder considerar su naturaleza" (Hegel, 1968, p. 42). Por la misma razón es insostenible la tesis que formula la validez de métodos de análisis absolutamente abstractos.

Todo método, si aspira a realmente ser efectivo en el conocimiento de un objeto, debe constituir la síntesis de las determinaciones de un contenido concreto. De lo contrario se corre el peligro de la siempre acechante especulación, por lo fácil que resulta incursionar en ese terreno y lo difícil que es escapar de sus atascos.

Si la filosofía aspira verdaderamente a ser útil, tiene que argumentar sus formulaciones sobre la más sólida base lógica que siempre revelará el contenido en última instancia concreto de las formulaciones teóricas más abstractas. Sólo si la abstracción se constituye en camino de tránsito necesario

este es el método que hoy se practica. El otro camino es el que remontando la sensación y de las cosas singulares provoca la aparición de los Axiomas, ascendiendo continua y gradualmente hasta llegar, por fin a los Principios de máxima generalidad. Este es el verdadero camino; pero no ha sido todavía puesto en práctica". Bacon, Francis. "Nuevo Órgano." En J. Marías. La filosofía en sus textos. Editorial Labor. Barcelona. 1963. p. 848. 
de lo concreto a lo concreto sobre nuevas bases teóricas, se justifica la empresa del filosofar.

En esta ardua labor la filosofía puede demostrar su función práctica, no sólo a través de las mediaciones necesarias del conocimiento científico sino de otras formas de la práctica social. En la medida que la lógica despliegue su capacidad como disciplina normativa y práctica, como la concebía Husserl (1967, p. 41), la filosofía podrá apoyarse en tan vital instrumento a fin de demostrar también su utilidad.

El hecho de que los temas axiológicos hayan tomado fuerza a partir de fines del siglo xIX no significa que la función valorativa-hermenéutica de la filosofía exclusivamente deba ser referida a partir de esa época. En todo momento la filosofía ha desempeñado dichas funciones para poder ser propiamente filosofía.

La utilidad de la filosofía ha sido apreciada por sus practicantes en la misma medida en que ha colaborado como instrumento efectivo de valoración e interpretación que posibilitan que el ser humano pueda apreciar mejor las obras de la naturaleza y las sociedades humanas, "Y si la filosofía tiene que ver con el amor, ella es también pasión por comprender y toda comprensión es un entrar en las cosas, dentro de ellas, conocerlas desde adentro, empáticamente podríamos decir. Así la realidad no aparece extraña, alienada" (Pachón, 2015, p. 164).

Para Platón las ideas constituían a la vez valores y en tal sentido cumplían un significativo papel en las relaciones sociales por la función paradigmática que desempeñaban al constituir modelos respecto a los cuales debían ser enjuiciadas las acciones humanas, especialmente las morales.

Por su parte, Aristóteles le concedió al valor un sentido más ontológico y vinculado a la fundamentación del ser de las cosas.

Los estoicos pusieron mayor atención a la cuestión de los valores en el terreno de la moral y fue en este ámbito de la ética en el que más los desarrollaron.

Aun cuando durante el Medioevo la preocupación por los problemas de los valores, al igual que por las interpretaciones, no ocuparon un lugar principal, a menos que fuese la interpretación de los evangelios, por cuanto se presuponía que el valor supremo era Dios y a partir de tal consideración toda valoración debía supeditarse a tal referente, también en tales circunstancias la filosofía no dejó de desempeñar su función valorativa y servir de instrumento a los objetivos teológicos. 
En la filosofía moderna tal función se fue haciendo cada vez más nítida y consciente en la misma medida en que era objeto de atención especial como se apreció en Hobbes. ${ }^{5}$

En Kant se produce una ruptura significativa en la evolución del pensamiento axiológico. Él es el antecedente inmediato de la axiología moderna, al considerar el hombre coexistiendo en dos mundos: el del ser y el del deber ser. Esta separación fue esencial y exigió, con el tiempo, una doctrina especializada en el estudio del deber (ley moral): la axiología que en Kant fue elaborada en su razón práctica, diferenciada de la razón teórica.

En Kant se evidenció una identificación entre el bien y el valor y una objetivación de su contenido, cuando expresaba: "Agradable llamase a lo que deleita; bello a lo que solo place; bueno, a lo que es apreciado, aprobado, es decir, cuyo valor objetivo es asentado" (Kant, 1990, p. 90), que posteriormente fue muy cuestionada por aquellos que se inspiraron en las bases de su filosofía e impulsarían el incremento de la preocupación axiológica y hermenéutica en la filosofía contemporánea.

A fines del siglo XIX, la cuestión axiológico-hermenéutica se convirtió en una de las preocupaciones principales de la filosofía. Ese incremento significativo en la toma de conciencia por esta problemática orientada a propiciar la valoración, la interpretación y el aprecio, no era más que una revelación del significativo papel de dicho problema que no se había desplegado en toda su riqueza en la filosofía anterior, aunque se encontrase subyacente de algún modo en todas sus precedentes manifestaciones.

Así Windelband planteaba que la filosofía no tiene como objeto los objetos particulares que componen el contenido del conocimiento empírico del ser humano. En su lugar, ella se ocupa de las normas a las cuales el pensamiento debe adecuarse para ser válidos y poseer el valor correspondiente.

A su juicio la filosofía "Sólo puede seguir viviendo como teoría de los valores universalmente válidos. [...] Tiene su propio territorio y su peculiar tarea en aquellos valores eternos en sí válidos, que constituyen la piedra de

5 El valor o estimación de un hombre es como el de todas las demás cosas su precio, es decir, tanto como sería dado por el uso del poder. Por consiguiente no es absoluto, sino una consecuencia de la necesidad y del juicio de otro." Hobbes, Tomas. Leviatán, I \& 10. Disponible en: http://www.uruguaypiensa.org.uy/imgnoticias/749. pdf 
toque de todas las funciones culturales y la espina dorsal de toda vida particular valiosa. Pero la filosofía sólo tiene que describirlos y explicarlos para dar cuenta de su validez: los manipula no cómo hechos sino como normas" (Windelband, 1943, p. 154). En tanto que para Rickert conocer es juzgar, aceptar o rechazar, aprobar o rechazar, en fin reconocer un valor.

Más allá de la polémica entre objetivistas y subjetivistas en cuanto a la existencia de los valores, lo cierto es que toda filosofía cumple una función axiológica-hermenéutica y ella ejercita al ser humano en el hábito permanente y necesario de la apreciación que siempre posee un carácter histórico condicionado por múltiples factores. Para Nicolai Hartmann, quien dedicó especial atención al asunto "No hay más manera de darse los valores que la conciencia del valor, bajo la forma del sentir el valor. Pero históricamente es mudable este sentir" (Hartmann, 1963, p. 442). A lo que se puede agregar que es histórico dicha apreciación del contenido de la valoración, porque histórico es también ante todo el sujeto de la valoración. "No hay valores porque hay valoración, sino al revés hay valoración porque hay valores" (Fabelo, 1993, p. 173), sostiene acertadamente José Ramón Fabelo en su acertada crítica a las tesis axiológicas de Risieri Frondizi.

De lo anterior se infiere que el humano es un ser preparado por el desarrollo social para ejercer la valoración y en tal desarrollo la filosofía cada vez más ha desempeñado una creciente función de preparar al ser humano para cumplimentar con mayor efectividad las tareas de enjuiciar y apreciar su entorno y su propio yo.

Pero resultaría absurdo pensar que el ser humano ejercita el filosofar simplemente por el placer de sentirse conocedor de la posibilidad de la elección tras la valoración.

La filosofía es ante todo instrumento que posibilita al ser humano ejercer una función hegemónica, de dominio, cooptación y control sobre el mundo natural y social. En nada contradice esta función a la emancipadora y desalienadora que también debe cumplir la filosofía en distinto plano, aunque no siempre lo logre y sólo quede como una encomiable intención.

En el desarrollo del pensamiento filosófico ha prevalecido el marcado deseo de propiciar al ser humano mecanismos que incrementen su poderío en todos los órdenes. En cierta forma la filosofía nace también como una necesidad de acrecentar el poderío del humano, que es puesto a prueba desde sus primeras manifestaciones como ser diferenciado del mundo natural. 
Dondequiera que hubiesen germinado ideas de corte filosófico indicaban que el ser humano había llegado a un grado de maduración técnica e intelectual que le posibilitara abstracciones más acabadas sobre los constantes problemas objeto de su reflexión.

En obras como el Tao te King de Lao Tse en la que se compendiaba la sabiduría no simplemente de un pensador aislado sino la acumulada por varias generaciones anteriores que también se cuestionaban similares temas, ya es evidente que una de las misiones esenciales de la filosofía es ofrecerle al ser humano posibilidades superiores de dominación de su entorno y de sí mismo.

Tal búsqueda de poderío no estuvo exenta de tergiversaciones, pues en ocasiones algunos llegaron a pensar que el dominio del ser humano sobre sí mismo, implicaba la renuncia al conjunto de placeres o de hábitos de vida diferenciadores de este respecto al mundo animal.

Ese es el caso de posturas anacoretas que fueron comunes en algunas manifestaciones del pensamiento filosófico de la antigua India, - que después se convirtieron en religiones como el budismo-, o en Grecia con los cínicos, que ilusamente consideraban que al llevar una vida similar a la de los perros podrían encontrar un grado mayor de libertad.

En realidad tales concepciones y prácticas, al alejar al humano de su progresiva condición de ser que constantemente debe humanizarse cada vez más, por el contrario lo convertían en un ser mucho más alienado y por tanto menos libre. Esto ya se aprecia en la crítica de Hegel a esta escuela del pensamiento griego (Hegel, 1955, p. 135). ${ }^{6}$ Pero se desarrolla mucho más en las consideraciones de Marx sobre la enajenación que produce la falsa imagen en el ser humano de sentirse en determinadas circunstancias más humano y libre cuando en verdad ejecuta funciones animales como comer, beber, descansar, procrear, entre otras, y paradójicamente sentirse más cerca del reino animal cuando realiza el "bestial" trabajo. A juicio de Marx, "El obrero solamente se siente fuera de su trabajo, y en su trabajo se siente

6 "La independencia de que los cínicos se jactaban tanto era, más bien, dependencia, pues mientras que toda otra esfera de la vida activa entraña el momento afirmativo de la libre espiritualidad, aquello equivale volver la espalda a la esfera en que puede disfrutarse del elemento de la libertad" Hegel, Guillermo, F. Lecciones sobre la historia de la filosofía. Fondo de Cultura Económica. México. 1955. T. II. p. 135. 
fuera de sí mismo. Se siente libre cuando no está trabajando, y cuando está trabajando no se siente libre" (Marx, 1965, p. 74).

Afortunadamente ese no fue el criterio que a la larga se impuso en la consideración de la utilidad de la filosofía. Pues en tal caso la pregunta sobre ¿para qué filosofar? hubiese tenido como respuesta final la paulatina desaparición no sólo de la filosofía sino del ser humano mismo.

Una de las mejores expresiones del criterio de que la filosofía constituye un especial instrumento de hegemonía fue la concepción platónica sobre el poder que debían tener los filósofos en su ideal de república o el conocimiento que debían tener de la filosofía los gobernantes para el mejor gobierno posible.

"Mientras los filósofos - proseguía Platón- no se enseñoreen de las ciudades o los que ahora se llaman reyes y soberanos no practiquen la filosofía con suficiente autenticidad, de tal modo que vengan a ser una misma cosa el poder político y la filosofía, y mientras no sean recusadas por la fuerza las muchas naturalezas que hoy marchan separadamente hacia uno de estos fines, no habrá reposo, querido Glaucón, para los males de la ciudad, ni siquiera, al parecer, para los del linaje humano" (Platón, 1968, pp. 368-369).

Esta función hegemónica de la filosofía llevó a Nietzsche, que lo diferenciaba sustancialmente de Marx (Guadarrama, 2005, pp. 47-90), a plantear que "Hay que tener mucho cuidado con los filósofos: ocultan siempre una vanidad, una satisfacción interior, por ejemplo Kant, Schopenhauer, los indos. O bien una voluntad de dominio, como Platón" (Nietzsche, 1957, p. 28)

Pero tal función hegemónica no debe reducirse de ningún modo al poder político o a otra dimensión ideológica, aunque por supuesto la presupone, sino al nexo de la filosofía con el resto de las formas del saber y en especial al de las ciencias como el que le atribuye Aristóteles a través de la lógica.

El cultivo más eficiente de la filosofía ha sido concebido en la mayoría de las ocasiones como la posibilidad del incremento del poderío humano sobre la naturaleza. Así, para Bacon, el hombre era concebido como ministro e intérprete de la naturaleza en cuanto obrara sobre ella conociéndola a través del uso de la experiencia y la razón, que le salve de las posibles especulaciones metafísicas derivadas de artificios silogísticos inadecuados.

Todo el ideal de la Ilustración se fundamentó en el poder que podía desplegar el ser humano si hacía un uso adecuado del saber equipado de las más acertadas concepciones filosóficas y científicas. Tarea esta que no siempre 
fue apreciada por sus consecuencias positivas, como en el caso de Rousseau, para quien las ciencias y las artes han sido engendradas por nuestros vicios y que la "filosofía fecunda siempre en máximas extravagantes" como la equívoca consideración que el lujo hace la grandeza y el esplendor de los Estados (Rousseau, 1973, p. 507). Sin embargo, la tendencia prevaleciente durante la Ilustración no fue precisamente esta, sino la contraría, que le atribuía una función muy progresiva a las ciencias, las artes y en especial a la filosofía.

El materialismo filosófico en Feuerbach aspiraba a sentar al ser humano en el trono del dominio no sólo de la naturaleza, sino de las presuposiciones sobrenaturales.

Marx aspiró a llevar ese dominio a una forma más concreta al tratar que la filosofía encontrara cuerpo en la clase social más revolucionaria de los nuevos tiempos: la clase obrera, por lo que sostenía en 1843: "Así como la filosofía encuentra en el proletariado sus armas materiales, el proletariado encuentra en la filosofía sus armas espirituales" (Marx, 1976, p. 30). Esa sería una de las vías por las cuales la filosofía podría lograr su hegemonía.

En tanto que los positivistas, por otros senderos, trataban por todos los medios que el poder burgués aún avanzara mucho más, convencidos de la utopía abstracta que por la entronización del individuo y con el poder de la ciencia y la técnica los conflictos sociales serían superados por un futuro estado de bienestar generalizado. A tal fin debía servir la filosofía del liberalismo que Stuart Mill (1987) preconizó partiendo del presupuesto de que "la única parte de la conducta de todo hombre de que es responsable ante la sociedad, es aquella que se relaciona con los demás. En lo que sólo concierne a él mismo, su independencia debe ser absoluta. Todo individuo es soberano sobre sí mismo, así como sobre su cuerpo y su mente". Ideal que el capitalismo aún oferta entre extraordinario mercado de fantasías (p. 32).

Ambas utopías, la socialista y la liberal, se pondrían a prueba durante todo el siglo xx y se mantienen en la mesa de laboratorio a inicios del siglo Xxi. El fracaso de algunos de sus experimentos, como en el caso de los más genuinos y consagrados científicos, no hace que abandonen sus proyectos a quienes están convencidos que debe aparecer una fórmula salvadora para la enferma sociedad contemporánea.

En aquel siglo XIX, tan generador de utopías y distopías, la filosofía pondría a prueba su condición de generadora de hegemonías, no siempre concebida para las mejores intenciones ni con la confianza suficiente en la capacidad 
perfeccionadora de las acciones humanas como en el caso de Nietzsche (1951), quien sostenía:

Y, en fin de cuentas, vuestro orgullo sin límites os hace acariciar también la esperanza demente de poder tiranizar la naturaleza, porque sois capaces de tiranizar vosotros mismos, pues el estoicismo es una tiranía infringida a sí mismo, como si el estoicismo no fuese el mismo un pedazo de la naturaleza. Pero todo eso es un cuento más viejo que la eternidad: lo que sucedió en otro tiempo con los estoicos se produce hoy mismo desde el momento en que un filósofo empieza a creer en sí mismo. Crea siempre el mundo a su imagen; no puede hacer otra cosa pues la filosofía es ese instinto tiránico, esa voluntad de dominación, la más intelectual de todas: la voluntad de crear el mundo, la voluntad de la causa primera. (p. 34).

La instrumentalización de algunas de estas ideas por ideologías totalizadoras dio como resultado amargas experiencias de ensayos políticos en el siglo $\mathrm{xx}$. Pero lo peor es que no siempre se extraen las adecuadas experiencias y parece, en ocasiones, como si la humanidad estuviese condenada a volver sobre los mismos pasos.

En la actualidad han tomado auge nuevas distopías como la del fin de la historia preconizado como el triunfo definitivo y eterno de la democracia liberal (Fukuyama, 1993, p. 387), en la que la función hegemónica, especialmente en su modalidad manipuladora, de la filosofía se expresa porque se pretende establecer una nueva y definitiva hegemonía que "ponga fin" a todas las hegemonías.

La filosofía no ha tenido como única misión la satisfacción de tareas de exclusivo carácter teórico. Desde que este tipo de saber se constituye, porta en sí una función práctica-educativa, aun cuando todas las apariencias indiquen lo contrario, cuya tarea principales se revelan en su intención de transformar, cultivar y superar al ser humano en cada época.

Tanto las concepciones éticas y gnoseológicas de Confucio como las de Sócrates tenían un fin eminentemente práctico-educativo. Así lo reconoció hasta el propio Hegel (1955) cuando afirmaba que "Puede, pues, afirmarse que, en lo que al contenido se refiere, la filosofía de Sócrates tenía una orientación totalmente práctica" (p. 51), cuyo sistema filosófico pudiera parecer 
lo más alejado posible de dicha función práctica y sin embargo resultó todo lo contrario, especialmente en el plano político.

Platón, quien constituye uno de los paradigmas de vinculación de su filosofía con la vida, y lo puso en práctica personalmente, consideraba que quien quisiera ser buen guardián de la ciudad debía ser ante todo buen filósofo, pues de otra forma no podría desarrollar con verdadera libertad y conocimiento tal función.

Un momento especial en la antigüedad en que se puso de manifiesto la articulación entre la filosofía y sus funciones prácticas fue en el período helenístico y en particular en la época romana. Tanto estoicos, como epicúreos constituyeron muestras evidentes de cómo la filosofía debía servir a la actuación práctica de cada individuo ante la naturaleza, lo sobrenatural, la vida política, moral, jurídica, entre otras, de aquellos tiempos.

La mayor parte de las concepciones filosóficas que tomaron auge en este período coincidían en considerar que el sentido principal de la existencia humana era alcanzar la felicidad y la filosofía estaba llamada a ser el instrumento principal para tomar conciencia de esa misión y facilitar su logro.

Marco Aurelio (1956) es uno de los exponentes de esa instrumentación práctica del filosofar cuando planteaba:

Pero aquel que aprecia la inteligencia suprema, la razón que rige el mundo y al género humano, no se inquieta de lo demás; sólo procura coordinar todas sus afecciones y sus movimientos con lo que le imponen esa razón universal y el interés de la sociedad, y ayuda a sus semejantes a que obre como el obra. (p. 62).

Tal vez uno de los momentos cuando se puso más a prueba la función práctico-educativa de la filosofía fue durante la Edad Media, pues en ese período tuvo que justificar su existencia como instrumentos práctico-ideológicos del dominio de la religión. Si no le hubiese servido a ese fin, no hubiese tenido la filosofía el cultivo que tuvo durante la escolástica y no tendría hasta la actualidad el apoyo con que cuenta en las religiones predominantes en el mundo contemporáneo.

Con el nacimiento de la modernidad la función práctica del filosofar se incrementó, pues la mayor parte de los filósofos comenzaron a generar utopías y proyectos de transformación social como en Moro, Locke, 
Montesquieu, y otros. Pero no solo en el orden político, también en el plano científico técnico comenzaron a germinar las ideas de la posibilidad de que la ciencia y la técnica se convirtieran en transformadoras radicales del mundo existente como en La Nueva Atlántida.

También en el seno de la producción filosófica latinoamericana tomaron auge tales ideas y se acentuó la función práctica de la filosofía. Entre los que sobresale en ese plano se encuentra el venezolano Andrés Bello ${ }^{7}$ quien sostenía que "El objeto de la Filosofía es el conocimiento del espíritu humano y la acertada dirección de sus actos" (Bello, 1948, p. 3), de tal modo expresaba su consideración de que la filosofía poseía una función también eminentemente práctica.

La Ilustración fue uno de los momentos de mayor auge de tales concepciones, se intentaba una aceleración progresiva del orden social burgués, aunque no se plantearan sustancialmente transformarlo pues este constituía aún una aspiración que revolucionaría las irracionales instituciones monárquicos-feudales que debían ser superadas por las "racionales" relaciones capitalistas de producción.

Sin embargo, entre los siglos XVI y XVIII proliferó el pensamiento metafísico y especulativo hasta el punto que varios filósofos, y no sólo desde posiciones materialistas sino desde el idealismo como Fichte, proclamaron la necesidad de la acción transformadora que debía cumplir la filosofía.

Ante ese reclamo y en una actitud crítico dialéctica con la filosofía anterior en la que el espíritu contemplativo parecía imponerse, a pesar de las sacudidas ocasionales de que había sido objeto, Marx exigió de la filosofía

7 El destacado filósofo mexicano Leopoldo Zea me comentó que al llegar a México en 1939 el pensador español José Gaos, -junto a otras personalidades republicanas de la cultura y la ciencia, que se vieron obligados al exilio con el triunfo de falangismo de Franco-, este tuvo la oportunidad de leer el libro de Andrés Bello Filosofía del entendimiento humano. Al quedar impresionado por la cultura filosófica del sabio venezolano exclamó que era una lástima que un pensador de esa talla hubiese nacido en Caracas, pues si hubiese nacido en cualquier pequeño pueblo de Inglaterra su obra hubiese figurado entre los clásicos universales del empirismo y los grandes sensualistas británicos como Locke, Berkeley o Hume. Es bien conocido que el carácter de "clásico universal" el eurocentrismo predominante aun en muchas partes se lo reserva solamente a los europeos y norteamericanos, en tanto los latinoamericanos, al igual que africanos, asiáticos, incluso los procedentes de Europa Oriental se les dificulta la posibilidad de optar por tal condición. 
una mayor actitud práctico-crítica con su tesis "los filósofos se han limitado a interpretar el mundo de distintos modos: de lo que se trata es de transformarlo" (Marx, 1965, p. 635).

Aunque era exagerado plantear que todos los filósofos se habían caracterizado por una postura contemplativa y no habían exigido una función más práctica a la filosofía, era cierto que se demandaba acentuar mucho más dicha función práctica, pues más que de una nueva filosofía en el sentido tradicional, o un nuevo sistema filosófico, se propugnaba un nuevo estilo de filosofar que pusiera en primer plano la crítica de todo lo existente para su más acertada transformación en su dimensión social y no exclusivamente ética.

Los positivistas por su parte trataron de encontrar una "solución" conciliatoria a las exigencias de transformación, necesarias indiscutiblemente, pero a la vez buscando conservadoramente que el "progreso" se produjese dentro del "orden" existente, es decir, la sociedad capitalista que idolatrada por el espíritu del liberalismo se creía haber descubierto el mejor de los mundos posibles.

Algunas derivaciones de esta escuela de pensamiento han buscado la función práctica del filosofar por otros derroteros, como la de servir de instrumento metodológico de compresión de la ciencia, o de esclarecimiento lógico de todos los saberes, entre otros. Esa ha sido la tarea emprendida por el positivismo lógico de Russel, Ayer, Witgenstein, Carnap, Schlick, y demás. Y en general por la filosofía analítica, que se considera a sí misma una filosofía científica (Reichenbach, 1975, p. 328) ${ }^{8}$ que se enfrenta a la tradicional o especulativa. En este caso, la preocupación por transformaciones de carácter social y político ha estado más ausente en esta corriente

8 "Y a pesar de todo, todavía hay filósofos que se niegan a aceptar la filosofía científica como una filosofía, que quieren incorporar sus resultados a un capítulo introductorio de la ciencia y que pretenden que existe una filosofía independiente, que no tiene nada que ver con la investigación científica y que puede alcanzar directamente la verdad. Estas pretensiones, creo yo, revelan una falta de sentido crítico. Los que no ven los errores de la filosofía tradicional no quieren renunciar a sus métodos o resultados y prefieren seguir un camino que la filosofía científica ha abandonado. Reservan el nombre de filosofía para sus falaces empeños en busca de un conocimiento supercientífico y se rehúsan a aceptar como filosófico un método de análisis construido sobre el modelo de la investigación científica". Reichenbach, Hans. La filosofía científica. Fondo de Cultura Económica, México. 1975. p. 328. 
de pensamiento. Lo cual no significa que desconozcan en ese plano la función práctica de la filosofía pero no la han estimulado por no considerar $\tan$ necesarias las transformaciones que otros desde la izquierda han demandado y ejecutado.

También el irracionalismo, en sus diversas manifestaciones, acentuó el aspecto práctico del filosofar, aunque por lo regular desde una perspectiva mucho más individual que social. Tanto Kierkegaard como Heidegger dedicaron lo mejor de sus energías intelectuales para proponer nuevos modos de vida para el humano que implicaran, a su juicio, una existencia auténtica.

Los defensores del postmodernismo (Guadarrama, 1994a) están convencidos de que la filosofía debe servir al acomodo del exitoso ser humano, fundamentalmente del primer mundo, y aquellos que en el tercero tienen la posibilidad de imitarlos, a los cambios que se han producido en el mundo actual, con la aceleración tecnológica, y los desafíos ecológicos, comunicativos y simbólicos, que traen aparejados.

Si el humano ha encontrado en el filosofar algún placer ha sido porque el cultivo de este tipo de saber le ha posibilitado no solo posibilidades de dominio, acción, transformación, valoración, conocimiento, y otros. Sino ante todo porque a través de la filosofía ha podido tomar mayor conciencia de su posible emancipación y ésta le ha permitido incrementar sus grados de desalienación.

Eso no significa que toda filosofía desempeñe igual papel emancipador, pues lo que para algunos pueda constituir alguna forma de liberación no necesariamente debe ser compartido por todos como efectiva forma de conquista de grados de libertad. Uno de los conceptos más difíciles de encontrar consenso entre filósofos, políticos, sociólogos, y hasta en las personas comunes es el de libertad.

No obstante, si es posible argumentar porqué algunas formas del filosofar han sido más desalienadoras que otras y a través de aquellas que han desempeñado un papel más protagónico, se puede comprender el sentido tendencialmente emancipador que ha tenido la filosofía desde su aparición hasta nuestros días.

Si el temor ha constituido en determinados momentos un ingrediente básico en la gestación de supersticiones y de ideas religiosas, el dominio del temor por la vía de la búsqueda de los argumentos más racionales de 
explicación a los fenómenos desconocidos ha posibilitado que la filosofía cumpla mejor su función emancipadora.

El budismo y el epicureísmo se destacaron en la antigüedad por sus respectivas propuestas de actitud a asumir por los seres humanos para que alcanzasen mayores grados de libertad, al propiciarles fórmulas intelectuales para superar el temor a la muerte, a las enfermedades, el dolor, a los dioses, entre otros. "Así, como en efecto, -sostenía Epicuro- la medicina no beneficia en nada si no libera de los males del cuerpo, así tampoco la filosofía si no libera de las pasiones del alma" (Mondolfo, 1971, p. 91).

El ideal socrático de conjunción entre ciencia y virtud que posibilitaba una mayor libertad se mantendría vivo en la filosofía, la cual le sucedió y está presente hasta nuestros días.

El fermento desalienador ha sido mucho más eficaz en pensadores materialistas y ateos como Holbach, porque ha propiciado una mejor actitud de los seres humanos ante el temor ante la muerte o ante los dioses.

[...] no hay cosa más útil que la de enseñar a los hombres a despreciar la muerte, y de apartar de sus entendimientos las falsas ideas que tiene de sus consecuencias. Este temor no constituiría más que cobardes y sus consecuencias: fanáticos o melancólicos, piadosos e inútiles para ellos mismos y para la sociedad. La muerte es un recurso que no debemos en ningún modo quitar a la inocencia oprimida, que la injusticia de los hombres reduce muchas veces a la desesperación. Si los hombres no la temiesen tanto, serían menos esclavos y supersticiosos, habría más defensores de la verdad; los derechos del hombre serían mejor sostenidos, se combatirían mejor sus errores, y la tiranía desaparecería para siempre de las naciones: la cobardía la nutre, el miedo la perpetúa, y, en una palabra, los hombres no pueden ni ser dichosos ni estar contentos mientras que sus opiniones les obliguen a temblar (Holbach, 1989, pp. 204-205).

Pero resulta insostenible pensar que todas las filosofías han cumplido cabalmente esa función liberadora, desalienadora y emancipadora, como ha sostenido Francisco Miró Quesada. No se puede asegurar lo mismo en relación a la patrística o la escolástica que en el caso del racionalismo cartesiano que situó a "la fuerza y evidencia de la razón" como criterio para establecer la mejor creencia (Descartes, 1971, p. 226). 
Ni es similar el tipo de liberación propugnado por Nietzsche que el de Marx y Engels. El primero, con el nihilismo que le caracterizó, propugnaba desde una perspectiva profundamente individualista: "Mi filosofía: !sacar a los hombres de la apariencia a toda costa! Y no tener temor alguno por el aniquilamiento de la vida" (Nietzsche, 1957, p. 96). Tampoco es comparable la misión emancipadora de la filosofía que ha estado concebida sobre bases muy diferentes en el peruano Augusto Salazar Bondy o en Leopoldo Zea (Zea, 1969, p. 159). Y en particular por la llamada filosofía latinoamericana de la liberación propugnada por Enrique Dussel (1988, p. 128). ${ }^{9}$

Una filosofía auténtica es aquella que contribuya a que el ser humano alcance en las circunstancias específicas en que se gesta mayores grados de dominio sobre el mundo que le rodea y sobre sí mismo (Guadarrama, 2009a, pp. 58-60). No todas las filosofías cumplen cabalmente con esa función, aunque todas de algún modo se lo planteen. La tarea del investigador consiste precisamente en determinar cuáles cumplen propiamente esa función y efectuar el balance necesario que permita finalmente constatar que, en sentido general, la filosofía ha desempeñado tal función emancipadora en su trayectoria universal.

Las filosofías son creaciones humanas cultivadas con intenciones, por supuesto, humanas, aun cuando los resultados no siempre, como en otras tantas ocasiones, no coincidan con aquellas. Incluso en aquellos casos en que los elementos misantrópicos hayan aflorado en mayor medida, no puede descartarse de antemano la presumida intención de comprensión de la naturaleza y la conducta humana que han servido de base a tales concepciones.

Toda filosofía se ha concebido a sí misma como la mejor propuesta para sugerir el comportamiento humano. Si las filosofías renuncian a la intención de intervenir activamente en el perfeccionamiento de la conducta humana dejan de ser filosofías. Por eso la función ética, cuya misión consiste en propiciar el adecuado comportamiento, reconocimiento, conducta del ser humano, es tan consustancial a la filosofía como las demás anteriormente esbozadas.

9 "Liberación no es simplemente estar en contra del centro, ni siquiera significa romper la dependencia. Es mucho más que eso es tener la creatividad de ser realmente capaces de construir la novedad, un nuevo momento histórico desde la positiva exterioridad cultural de nuestro pueblo". Dussel, Enrique. Introducción a la filosofía de la liberación. Editorial Nueva América. Bogotá. 1988. p. 128. 
Esto se aprecia a lo largo de su historia a través de múltiples manifestaciones. Unos filósofos le han dedicado más atención que otros al asunto, pero todos de algún modo han abordado el problema de las normas que deben regir la moral y el comportamiento real que el humano tiene en las distintas situaciones.

Algunas escuelas filosóficas le otorgaron tanta atención al problema de las reglas de conducta moral del ser humano que prácticamente este tema se convirtió en el eje principal de convivencia comunitaria de los seguidores de las doctrinas del maestro que las propugnaba. Los casos de Confucio, Pitágoras y Sócrates se encuentran entre los más paradigmáticos en la antigüedad, aunque pueden también considerarse a los estoicos y epicúreos.

Para Confucio la rectitud debía constituir la sustancia del ser humano, la decencia la base de su conducta, la modestia su punto de partida y la honestidad su meta (Brehier, 1962, pp. 201-211). No es extraño que estas máximas se convirtieran en preceptos éticos cultivados posteriormente por la interpretación religiosa del confucianismo, que ha llevado a considerar el confucianismo como una religión exclusivamente, subestimando el carácter filosófico del contenido de las ideas de aquel pensador.

El nexo entre filosofía y virtud se apreció tanto en el Oriente antiguo, China, India, y otros, como en Grecia, desde sus primeras manifestaciones en Pitágoras, a quien se le considera fue uno de los primeros en autodenominarse filósofo y estableciendo la comparación entre la vida humana y un concurso festivo donde acuden todo tipo de gentes dijo "pues así como unos vienen a él a luchar, otros a comprar y vender y otros, que son los mejores, a ver; también en la vida unos nacen esclavos de la gloria, otros cazadores de los hombres, y otros filósofos, amantes de la virtud" (Diogenes, 1990, p. 206). Así el cultivo de las virtudes se convertiría en una de las tareas principales que tendría ante sí en orgánica articulación con la misión práctica la filosofía griega.

A partir de la enseñanza de Sócrates de que "el hombre virtuoso es aquel que sabe calcular y escoger los placeres", para que no se conviertan en su contrario, Platón ponía en boca de su maestro la tesis de que "todo hombre está obligado a ser virtuoso, para que la sociedad subsista" (Platón, 1946, p. 304). Y con ese fin deben equilibrarse el placer y la inteligencia para que pueda salir victorioso "el bien en el hombre" (Sócrates, 1946, p. 596). 
Su discípulo Aristóteles continuaría ese culto a las virtudes, pero convencido de que el logro de la forma superior de vida era la teorética, en la que se pudiesen cultivar la filosofía y la ciencia que posibilitarían la felicidad plena. "Vivir bien y obrar bien no es otra cosa que la felicidad: luego ser feliz y la felicidad están en vivir bien. Y vivir bien consiste en vivir de acuerdo con la virtud. La virtud es por tanto el fin, la felicidad y lo mejor" (Aristóteles, 1964, p. 42). Esto es, la verdadera felicidad -o al menos la toma de conciencia de su significación cabal- la reservaba el estagirita para "el hombre sabio", para el filósofo.

Tanto los cínicos como los estoicos consideraban a la filosofía como ejercicio y estudio de la virtud, aunque los primeros no le dedicaran real atención a la profundización teórica del asunto, sino sólo incorporarlo a su anacoreta norma de vida, en tanto que los estoicos más a tono con el espíritu socrático y al igual que Epicuro, le otorgaban al cultivo de la filosofía y al conocimiento en general un papel primordial para que "el hombre pudiese vivir según la razón” (Mondolfo, 1971, p. 313) ${ }^{10}$ como era su máxima.

La manifestación de la función ética de la filosofía, al igual que las demás funciones, no ha sido en todas las épocas de la misma magnitud.

En una época de crisis de valores y de confusión en cuanto a las normas morales es comprensible que la preocupación filosófica por la ética se incremente por sí misma. Sin embargo, durante la Edad Media esa función estuvo subordinada a la dominación religiosa que impuso un determinado esquema de conducta. Aprisionada en tan estrechos marcos la función ética

10 "Por ello debe dominar la razón, que es presencia del logos universal en el alma individual. Ella debe impedir las perturbaciones de los impulsos irracionales (pasiones): el ideal del sabio, o sea la virtud es la extirpación de las pasiones (apatía) y la imperturbabilidad (ataraxia); porque las pasiones, en su irracionalidad, son todas errores y enfermedades del alma o sea vicios; no sólo aquella que condena la opinión común (ira, temor, avidez, etc.), sino también aquellas que ella juzga impulsos loables, como la piedad, los afectos individuales, las ansias y aflicciones por calamidades privadas o públicas. Su error e irracionalidad está en el aislamiento del fin particular del universal, mientras que el sabio debe considerar las cosas siempre no en su particularidad, sino en el orden y la armonía del universo, en el cual las valoraciones de lo incipiente pueden transmutarse, o aquellos que para él son valores, pueden resultar indiferentes (vida y muerte, salud y enfermedad, placer y dolor, riqueza y pobreza, etc.); mientras que bien y mal no permanecen siendo niño la virtud y el vicio”. Mondolfo, Rodolfo. T. II. p. 313. 
estuvo limitada a estimular una concepción muy reducida de lo que se consideraba constituía el paradigma de la beatífica conducta humana.

La modernidad abrió las puertas a una pluralidad de modelos de seres humanos, aunque partiese del endeble presupuesto de la igualdad entre ellos. El culto a la libertad favoreció que la función ética retomara su capacidad autónoma con el carácter laico que le propugnó la Ilustración.

A partir de ese momento se perfilaron tendencias contrapuestas respecto a la naturaleza humana, que incidieron directamente en la nueva función ética que se le demanda a la filosofía.

Aquellas consideraciones de que "el hombre es el lobo del hombre" (Hobbes) o que es un egoísta e individualista por naturaleza, no podían estimular la misma función ética que propugnaban las que han confiado en su presunta bondad natural. Al igual que las concepciones que abogan por una visión diferente a las dos anteriores, y al parecer más cercana a la real, donde no lo considera ni bueno, ni malo por naturaleza predeterminada, sino humanizable en su capacidad perfectible a través no solo de la educación y cultura, sino también por medio de revolucionarias transformaciones sociales que lo conduzcan intentar realizar los criterios comunistas de alcanzar cierta forma de sociedad más justa y equitativa.

En la actualidad, cuando se han puesto en crisis los presupuestos de la modernidad y son cuestionados tanto los fundamentos del liberalismo, en sus nuevas modalidades, como los de ciertas interpretaciones del ideal comunista, han fructificado las creencias postmodernistas que de manera ilusoria aspiran a "solucionar" el problema renunciando al empeño del cultivo de la función ética y al humanismo.

Las funciones axiológica, hegemónica, práctico-educativa, emancipadora, ética y estética quedan subsumidas en la función axiológica y articuladas a la función ideológica, si se entiende esta última no como falsa conciencia o simple imagen pretensiosa de la realidad social, sino como conjunto de ideas que conforman la concepción de una clase o grupo social y están dirigidas al sostenimiento o realización de su poder respecto a toda la sociedad o al menos a nombre de ellas.

Ninguna filosofía se puede reducir a que sea considerada exclusivamente como una ideología. Pero tampoco ninguna filosofía ha podido escapar a su función ideológica según la cual ésta se propone orientar, disponer, manipular y convocar a la construcción de modelos de organización sociales. 
Múltiples son los ejemplos que atestiguan desde la antigüedad que los filósofos siempre han pensado y actuado sin desatender los móviles ideológicos.

En definitiva, toda filosofía ha aspirado a conformar un modelo social superior y a hacer todo lo posible para que se realice. En ocasiones el fermento ideológico ha podido afectar el grado de objetividad de las consideraciones teóricas de los pensadores. Nadie ha podido escapar de aquellos impulsos que inducen a considerar el proyecto propio de restauración social como el mejor de todos los tiempos.

Cuando la carga ideológica ha sido desproporcionada el efecto de dicha función lejos de favorecer la ha entorpecido y en ocasiones hasta produce el efecto contrario al deseado por el filósofo-ideólogo.

A su vez, aquellos que han pretendido escapar de las ideologías y refugiarse en una esfera absolutamente desideologizada, también por lo común, han producido un efecto opuesto y sus lectores han detectado fácilmente el doblez del disfraz.

Ha sido más efectivo cuando los filósofos han expresado de un modo más diáfano las propuestas ideológicas que se derivan de sus formulaciones teóricas como en el caso de Maquiavelo, Rousseau, Marx o Nietzsche, que cuando han pretendido escamotearlas.

En ocasión de que Juan Bautista Alberdi (1986, p. 150) ${ }^{11}$ reclamaba que la filosofía en América debía poseer un contenido eminentemente político, no lo hacía para producir aceptación entre apetitosos consumidores de ideología, sino porque interpretaba cabalmente las demandas de sus circunstancias, pues pareciera que "ya no se quiere prácticar filosofía sin más, sino que se busca justamente la contextualización e inculturación de la reflexión filosófica” (Beorlegui, 2004, p. 39).

11 "Nuestra filosofía, pues, ha de salir de nuestras necesidades. Pues según estas necesidades, ¿cuáles son los problemas que la América está llamada a establecer y resolver en estos momentos?- Son los de la libertad, de los derechos y goces sociales de que el hombre puede disfrutar en el más alto grado en el orden social y político; son los de la organización pública más adecuada a las exigencias de la naturaleza perfectible del hombre, en el suelo americano. De aquí es que la filosofía americana debe ser esencialmente política y social en su objeto; ardiente y profética en sus instintos; sintética y orgánica en su método; positiva y realista en sus procederes; republicana en su espíritu y destinos." Alberdi, Juan Bautista. "Ideas para un curso de filosofía contemporánea". Ideas en torno de Latinoamérica. UNAM. México. 1986. p. 150. 
De la misma forma, Augusto Salazar Bondy deseaba dignificar el estatus académico de la producción filosófica en América Latina, pero no dejaba de reconocer la necesaria carga política que poseía la filosofía en esta región, como en otras latitudes, aunque no de un modo tan manifiesto.

Cuando los filósofos han ejercitado su intelecto no solo para interpretar sino para modelar la realidad lo han hecho también con marco referencial de criterios estéticos, que han tratado de trasladar a su objeto de análisis, aun cuando no fuese el arte su terreno de análisis. De ahí la función estética que desempeña siempre la filosofía al tratar establecer criterios sobre el gozo, disfrute, deleite, gusto y estimulación del ser humano ante sus creaciones y las de la naturaleza.

Algún criterio de belleza y de satisfacción del gusto han estado presentes en la articulación de las ideas filosóficas más exigentes.

El filósofo se ha sentido responsable de ofrecer criterios de valoración estética que presupone deben ser asumidos por todos para la mayor satisfacción de toda la sociedad. La pretensión de universalidad se revela tanto en las producciones artísticas como en los criterios de que la filosofía desea apertrechar al ser humano para que se sienta también acreedor de esta forma de placeres.

Unos han buscado la belleza en las ideas mismas, como Platón en su Fedro, otros en el orden y la simetría que se percibe como Aristóteles, tomando como referencia presupuestos eminentemente humanos. Por su parte, la escolástica establecería el origen divino de los criterios de lo bello; y el laico pensamiento moderno se encargaría de quebrantar su nexo con Dios, para establecerlo con la naturaleza (Kant, 1990, p. 166).

En tanto, los ilustrados latinoamericanos como Benito Díaz de Gamarra dejaron plasmados sus consideraciones de la función estética de la filosofía cuando a mediados del siglo xvir sostuvo que "la filosofía [...], es el conocimiento de lo verdadero, de lo bueno y de lo bello, adquirido con la sola luz de la naturaleza y con el raciocinio de ahí derivado" (Díaz, 1963, p. 25).

Lo cierto es que por doquier el ser humano busca criterios de belleza y trata de producir y pensar tomando como criterio el gusto por la belleza y no sólo el criterio de necesidad.

En un espacio terráqueo en que cada vez el entorno natural se reduce y se comienzan a apreciar los efectos negativos del antropocentrismo desequilibrado frente al medio ambiente, y la acción humana se expande incluso más 
allá de este planeta, es lógico que junto a los criterios ecológicos y humanistas, los criterios estéticos se expandan también progresivamente y con ellos las consideraciones filosóficos que demandan.

Pero resulta paradójico que mientras la comunidad internacional ha discutido en los últimos años arduamente si debe crear o no un alto comisionado para enjuiciar las violaciones de los derechos humanos que se cometen en el mundo, algunas filosofías, hayan querido inaugurar y despedir el pasado siglo xx poniendo en la picota el humanismo.

Desde que la filosofía se constituyó en actividad intelectual específica la función humanista ha estado presente como elemento consustancial a toda reflexión cosmovisiva cuya misión consiste en tratar de perfeccionar al ser humano, hacerlo progresar en sus relaciones con sus congéneres y humanizarlo lo más posible; no obstante las posibles taras de otra naturaleza a la humana que se revelan en algunos individuos de esta especie.

Aunque no han faltado momentos en el devenir de aquella en los que el lugar de la problemática antropológica ha sido desplazada, como en el medioevo, o en que la condición humana ha sido cuestionada ante evidencias de imperfección, y otras; ha prevalecido como tendencia regular la confianza en la perfectibilidad humana y en el papel enriquecedor de la moral.

Nietzsche abrió los ataques contra aquellas concepciones que conciben la existencia de una progresiva trayectoria del género humano. A su juicio constituía un gran error "considerar al hombre actual (Europa) como el tipo superior humano" (Nietzsche, 1957, p.292), ya que para él los griegos y los hombres del Renacimiento eran hombres superiores a los actuales y el incremento de la moralidad en lugar de enaltecer al ser humano había marcado su decadencia.

Tal concepción del desarrollo humano estaba dirigida contra cualquier intento de elevar al humano a niveles más dignos de existencia, que no fuese el cultivo del arrogante afán de poder, especialmente del europeo, para quien, según su criterio, debía construirse la historia. Por el hecho de partir de una postura marcadamente misantrópica su filosofía constituye la antítesis de todo humanismo. No en balde inspiró y aún inspira a algunos movimientos fascistas y xenofóbicos.

No resulta casual tampoco que Heidegger, quien contribuyó notablemente en su célebre carta "Sobre el humanismo" a la divulgación de la idea de la crisis de éste, al vincularlo al ocaso de la metafísica, haya coqueteado 
con el régimen nazi, dando pruebas también de que este debate no se circunscribe al mundo de la teoría.

En la actualidad cuando el fracaso del "socialismo real" se identifica como la consumación de la inutilidad del humanismo, la filosofía postmodernista busca innumerables argumentos para acentuar la tesis sobre la presumida causa perdida del humanismo.

La renuncia a esta concepción está unida a la conformista concepción que presupone abandonar cualquier proyecto que se proponga niveles superiores de desalienación humana. Pues, como asegura Lyotard, "El recurso a los grandes relatos está excluido; no se podría pues, recurrir ni a la dialéctica del Espíritu ni tampoco a la emancipación de la humanidad para dar validez al discurso científico postmoderno" (Lyotard, 1989, p. 109). Queda claro que ser "científico" entonces presupone aceptar el mundo tal y como está y no proponerse mejorarlo en un ápice, como índice de la mejor forma de contemplativa interpretación teórica del mundo.

La cuestión no sólo trasciende a los planos sociopolíticos donde indudablemente siempre resulta más comprometida y riesgosa, sino que llega a todos los órdenes de la sociedad contemporánea, pues a juicio de Vattimo la crisis del humanismo está relacionada "con el crecimiento del mundo técnico y de la sociedad racionalizada"(Vattimo, 1990, p. 36). Siguiendo esta lógica la humanidad estaría condenada fatalmente al ocaso de los valores humanistas, a menos que esté dispuesta a renunciar a seguir cultivando la ciencia, la técnica y el racional aprovechamiento y ordenamiento de la vida social, conquistas estas que la humanidad no estará nunca en disposición de echar por la borda.

Por otro lado, resulta más preocupante que la resignada aceptación de un deterioro del humanismo, concebido en su sentido académico más genérico, pueda servir de justificación a prácticas que alejen al ser humano del humanitarismo, de la filantropía, que usualmente han acompañado al primero.

Nikolai Berdiaeff (1947) planteaba que "El fin del humanismo señala también el fin del humanitarismo" (p. 25). Esto último es lo que puede resultar más preocupante en las actuales circunstancias cuando las brechas de desarrollo económico entre los países del Norte y el Sur, y entre los reducidos sectores sociales dominantes y los amplios populares dentro de unos y otros, se acrecienta con la oleada neoliberal. 
El humanismo entendido en su formulación más amplia ha encontrado innumerables definiciones (Guadarrama, 2001a). Usualmente se maneja en su expresión clásica histórica como ese movimiento cultural que se despliega en la época renacentista entre aquellos intelectuales, profundos admiradores de la cultura grecolatina, que intentaban rescatar la dignidad humana tan atrofiada por siglos de servidumbre y teocentrismo. En tal caso se presenta como un nuevo tipo de "fe en los valores humanos hechos para el hombre, y por tanto trascendencia del logos" (Toffannin, 1953, p. 514). Por lo que no se diferenciaría mucho de otro tipo de religiosidad, en tal sentido antropocéntrico, lo cual no deja de implicar algunos riesgos.

Algo más apropiado sería concebirlo en sentido general, según Gaspar Jorge García Galló como "un conjunto de ideas que destacan la dignidad de la persona, la preocupación por su desarrollo armónico y la lucha por crear condiciones favorables al logro de tales fines" (García, 1989, p. 118). En este caso se acentúa mucho más el carácter activo del humano como sujeto transformador de sus condiciones de existencia en correspondencia con ideales de vida dignos.

El humanismo no constituye una corriente filosófica o cultural homogénea. En verdad se caracteriza en lo fundamental por propuestas que sitúan al ser humano como valor principal en todo lo existente y partir de esa consideración, subordina toda actividad a propiciarle mejores condiciones de vida material y espiritual, de manera tal que pueda desplegar sus potencialidades siempre limitadas históricamente.

La toma de conciencia de estas limitaciones no se constituye en obstáculo insalvable, sino en pivote que moviliza los elementos para que el hombre siempre sea concebido como fin y nunca como medio. Sus propuestas están dirigidas a reafirmar al ser humano en el mundo, a ofrecerle mayores grados de libertad y a debilitar todas las fuerzas que de algún modo puedan alienarlo.

Todo poder supuesto a fuerzas aparentemente incontroladas por el ser humano, que son expresión histórica de incapacidad de dominio relativo sobre sus condiciones de existencia y engendradas consciente o inconscientemente por el ser humano, limitando sus grados de libertad, se inscriben en el complejo fenómeno de la enajenación.

Desde el mundo antiguo aparecen manifestaciones precoces que indican la preocupación humanista y desalienadora del ser humano, aun cuando no 
hayan sido formuladas en tales términos. Tanto en la China y en la India, donde la ética alcanzó niveles impresionantes desde la antigüedad, como en las culturas amerindías (Guadarrama, 2012a, pp. 127-153), y de otras latitudes hay evidencias del privilegiado lugar que se le otorgó siempre al ser humano, incluso cuando se subordinara su existencia a la creación divina.

Confucio y sus discípulos preferían rechazar toda especulación sobre el universo para "hacer del hombre el objeto propio del saber" (Granet, 1959, p. 338), ${ }^{12}$ a tenor con las ideas humanistas que profesaban. En la India prevaleció una concepción eminentemente dinámica del ser humano, opuesta a la pasividad que se observaba por lo regular en otras culturas (Masson, 1957, p. 192). Sin embargo, el desmedido elogio de los indiscutibles valores de la cultura griega conduce en ocasiones a hiperbolizaciones, tales como la de considerar que estos fueron los primeros en preocuparse por los problemas eminentemente humanos (Turner, 1979, p. 563), ${ }^{13}$ desconociendo de esa manera los extraordinarios aportes de otras culturas antiguas, tanto orientales como "occidentales", a la conformación del pensamiento humanista.

Es evidente que también fueron comunes al humanismo antiguo determinados rasgos pesimistas (Klaus, 1970, p. 484) y lamentaciones que reflejaban cierto malestar de algunos sectores sociales por las relaciones esclavistas prevalecientes y las formas humillantes que estas presuponían para gran parte de la población. Sin embargo, la mayoría parte de la intelectualidad que profesaba ideas humanistas, se encontraba en una ventajosa situación socioeconómica que le permitía apreciar la situación del ser humano en el mundo desde una perspectiva optimista, aun cuando filantrópicamente llegasen algunos hasta manifestar sus deseos por mejorar la situación de los más sufridos.

No es menos cierto que fue en la cultura griega donde el humanismo alcanza en aquella época ribetes descollantes. Este hecho se evidencia desde el mismo momento en que la preocupación cosmogónica y cosmológica

12 "Para ellos, el principio de este saber único interesante y el único eficaz, era la vida en sociedad, el trabajo del conocimiento, de vigilancia, de perfeccionamiento proseguido en común, la cultura humanista, gracias a la cual el hombre se constituye en dignidad”. Granet, Michel. El pensamiento chino. UTEHA. México. 1959. p.338.

13 "Probablemente el común denominador de los aportes de los griegos a la alta tradición intelectual de occidente fue el descubrimiento del hombre." Turner, Ralph. Las grandes culturas de la humanidad. Ediciones Revolucionaria. La Habana. 1979. p. 563. 
fue cediendo terreno a la antropológica, a través del giro llevado a cabo por los sofistas y en particular por Protágoras con su sentencia "El hombre es la medida de todas las cosas" (Platón, 1946, p. 660).

Pero junto al pensamiento humanista en la antigüedad se fueron conformando paulatinamente a su vez los gérmenes de lo que hoy en día denominaríamos elementos desalienadores. La alienación humana siempre presupone, antes de su despliegue pleno, la constatación de temores, indecisiones, incapacidad, impotencia por ignorancia, entre otros, factores estos que empequeñecen y limitan al ser humano. El pensamiento humanista por su naturaleza emancipadora es la antítesis de esas actitudes, sin embargo, en su devenir no puede evadirse de ir acompañado de tales rasgos debilitadores que atentan contra el carácter afirmativo del ser humano en el mundo.

La simple toma de conciencia de esas manifestaciones de obstáculos al amplio desarrollo de la libertad humana, no constituye la actitud decisiva para su superación, pero al menos se convierte en factor propiciador para que otros pensadores, y lo que es más importante, líderes, políticos, funcionarios, y otros actores, se esfuercen por realizarla en sus respectivos radios de acción.

Así por ejemplo, la inconmensurabilidad de la actividad consciente siempre ha preocupado a los filósofos desde la antigüedad hasta el presente y aunque muchos de ellos, como Heráclito (Marías, 1963, p. 27), ${ }^{14}$ Berkeley, Spencer, entre otros, hayan puesto límites a la posibilidad del ser humano de conocer el mundo y a sí mismo, ninguno paralizó su labor intelectual dirigida en última instancia a ofrecerle herramientas epistémicas y éticas para conformar una vida superior.

La filosofía se ha ido construyendo en su historia universal como un permanente proceso de aportación parcial por parte de sus cultivadores de distintos instrumentos desalienadores que contribuyen en diferente grado a la consolidación del lugar del ser humano en el mundo. Cuando han

14 "Pero los mortales creen que los dioses tienen un nacimiento y vestiduras, voces y cuerpo similar al de ellos. Y los etíopes representan a sus dioses chatos y negros, y los tracios dicen que tienen ojos azules y los cabellos rojos. Pero si los bueyes, los caballos y los leones tuviesen manos y con ellas pudiesen dibujar y realizar obras como los hombres, los caballos dibujarían figuras de dioses semejantes a los caballos, y los bueyes a los bueyes, y formarían sus cuerpos a imitación del propio". Mondolfo, Rodolfo. El pensamiento antiguo. Editorial Ciencias Sociales. La Habana. 1971. p. 189. 
constatado los distintos peligros enajenantes, que en circunstancias diversas afloran en la vida humana, han aportado en la mayor parte de los casos las vías para superarlos.

No es menos cierto que no han faltado quienes se han limitado a constatar o a poner de manifiesto formas enajenantes, como la subordinación al poder de los dioses, de los gobernantes, de las fuerzas ocultas de la naturaleza, entre otras. Sin contribuir mucho a encontrar los mecanismos para evadirlos, porque han partido de la fatal consideración de que estos son consustanciales a la condición humana. Pero de haber prevalecido estos criterios fatalistas en la historia de la civilización, hoy difícilmente podrían las nuevas generaciones humanas enorgullecerse de los avances alcanzados en todos los órdenes de perfeccionamiento social.

Pero aun aquellos pensadores que se limitaron a plantear algunas de las modalidades que adquirían las distintas formas de enajenación y no dieron otros pasos para superarlas, prepararon el camino y sirvieron de premisa a sucesores más audaces que avanzaron algo más en el proceso desalienador del humano.

Cuando Jenófanes evidenciaba que los seres humanos de las distintas culturas han imaginado a sus dioses con los rasgos antropomórficos de los habitantes de las regiones que habitan (Mondolfo, 1971, p. 189), ${ }^{15}$ preparaba el camino a Epicuro, y en especial a Feuerbach y a Marx, para análisis superiores sobre la enajenación religiosa. Pero su labor no fue de simple constatación, sino también de sugerencia para que la acción humana no cesara en su incansable búsqueda.

El criterio de que el humano debe ser el principal artífice de su autoperfeccionamiento impregnó todo el pensamiento del antiguo Oriente, como se observa en Confucio y en Grecia donde estuvo presente hasta en filósofos antagonistas como Platón y Demócrito. Este último sostenía con acierto que "La primera y mejor de todas las victorias es vencerse a sí mismo" (Mondolfo, 1971, p. 138).

Consecuente con ese criterio fue Epicuro al desear emancipar al humano de su propensión hacia el vicio de los placeres. También quiso otorgarle

15 "A la perfección de los dioses, que realiza el supremo ideal del sabio, debe ser dirigido un culto desinteresado de admiración, no el culto servil de la imploración y de los conjuros, constituido por el interés y el temor". T.II. p.308. 
un digno lugar en su relación con los dioses al mantener a estos alejados de las vicisitudes terrenales (Mondolfo, 1971, p. 308). ${ }^{16}$ Similar actitud potencializadora y dignificadora del humano, que no es otra cosa que contribución desalienante, asumió también en su cuadrifármaco ante el temor a la muerte, el dolor, las enfermedades, y otras. No fue simple casualidad que Marx, quien hurgó en planos más profundos de la enajenación, eligiera a ambos pensadores para su tesis doctoral en filosofía (Marx, 1991, p. 121).

El tema de la superación de la enajenación que producen los placeres mundanos en el humano estuvo presente también en los representantes del idealismo, como es el caso de Platón (1946, p. 573). ${ }^{17}$ Pero no es posible considerar en un mismo grado los elementos desalienantes que se dan en pensadores idealistas, que los que se dan en materialistas como Demócrito o Epicuro, por el grado de trascendencia y objetivación que aquellos le otorgan a las ideas, entidades e instituciones, razón la cual, no obstante coincidir en la creencia en los dioses, difieren sustancialmente en cuanto al lugar que ocupan por sus concepciones religiosas. Sin embargo, sus puntos de coincidencia en determinados aspectos humanistas y desalienadores son innegables.

Platón, por ejemplo, aspiraba también a que el humano lograse al máximo un equilibrio armónico entre las distintas partes de su alma para que se hiciese "dueño de sí mismo" (Platón, 1946, p. 217). Aun cuando pudieran diferenciarse los grados de dependencia que el humano establecía con las distintas entidades, especialmente las divinas.

16 En la fundamentación de su elección Marx argumenta que : "Puesto que todos los filósofos antiguos partieron de la conciencia, como de presupuesto- sin exceptuar a los escépticos- siempre les hizo falta un punto seguro de apoyo; tal función la cumplen las representaciones, tal como se hallan en el saber general. Epicuro, en cuanto filósofo de la representación es, en este punto, el más riguroso, y define por eso, mejores tales condiciones de fundamento. Es, además el más consecuente, llevando así, como los escépticos, por otra parte, a su perfección a la filosofía antigua" Marx, Carlos. "Tesis doctoral”, en Marx, C. y Engels, F. Categorías fundamentales (1836-1844).Ediciones del Rectorado de la Universidad Central de Venezuela. Caracas.1991. p.121.

17 "La sabiduría, la inteligencia, la memoria y todo lo que es de la misma naturaleza, la justa opinión y los razonamientos verdaderos son, para todos los que lo poseen, mejores y más apreciables que el placer a la par más ventajoso a todos los seres presentes y futuros, capaces de participar de ellos". Platón. Obra Completas. T.I. p.573. 
Unos y otros han concebido al humano como un eterno insatisfecho con sus conocimientos, razón por la cual se ha planteado siempre enriquecerlos, aunque presuponga que jamás podrá alcanzar la sabiduría perfecta. Aristóteles inicia su Metafísica, partiendo del criterio de que "Todo hombre, por naturaleza, apetece el saber" (Aristóteles, 1968, p. 33). Su colosal obra enciclopédica es una muestra de proyecto humanista, porque está dirigido a ofrecerle al humano el mayor conocimiento posible alcanzado en su época sobre las más diversas esferas del saber humano.

Su intención desalienadora por la vía epistémica es marcada, pero también lo es cuando propone formas superiores de gobierno político que superen las enajenantes modalidades de oligarquías y tiranías. A pesar de que en otros planos como el cosmológico y el antropológico quede atrapado en ocasiones por su rígida imagen del universo y por su "naturalista", teleológica y enajenante concepción de la esclavitud (Aristóteles, 1968, p. 375) ${ }^{18} \mathrm{su}$ máxima aspiración, como queda plasmada a través de toda su ética, es lograr un "hombre virtuoso y digno" (Aristóteles, 1964, p. 100) ${ }^{19}$, que se enaltezca permanentemente. El cultivo de la dignidad humana, más allá de limitaciones clasistas, constituyó un elemento sustancial en su pensamiento social que le hace ocupar un sitio destacado en la trayectoria del humanismo antiguo.

La lucha del humanismo frente a las tendencias enajenantes opositoras fue adquiriendo en la filosofía romana nuevos ribetes. El primero trataba de

18 "El que por naturaleza no pertenece a sí mismo, sino a otro, siendo hombre, ese es naturalmente esclavo." Aristóteles. Metafísica. Política. La Habana: Editorial Estudios. 1968. p. 375. Más que naturalista esta visión aristotélica es teleológica y fatalista como toda su filosofía.

19 "La dignidad ocupa una posición intermedia entre la autosuficiencia y la cortesía servil. Su campo es el de las relaciones e intercambios de la vida social. El hombre suficiente es el que evita todo intercambio y conversación con sus semejantes o compañeros; su verdadero nombre parece haberle sido dado por esta característica, porque el autosuficiente es el que se basta a sí mismo. Por otra parte, el hombre servilmente cortés u obsequioso quisiera tratar y frecuentar a todos los hombres de cualquier manera y en cualquier circunstancia. Ninguno de ellos merece encomio. Pero si la merece el hombre digno, que guarda una posición intermedia entre ambos. Este, en efecto, ni trata con todos los hombres, ni huye el trato de todos: trata con los que tienen un mérito o son dignos de ello, y tan solo con ellos" Aristóteles. Gran ética. Aguilar. Madrid. 1964. p.100. 
mantener viva la tradición desalienante de pensadores como Tito Lucrecio Caro (1968, p. 273)..$^{20}$

Mientras que los elementos enajenantes afloraban de manera temprana en la era cristiana en varios pensadores, entre ellos un esclavo-filósofo como Epicteto (1963, p. 206). ${ }^{21}$ Ese sería el nuevo sesgo que irían tomando las reflexiones antropológicas durante varios siglos.

La visión humanista del mundo y con ella tal función de la filosofía sufrió una fuerte sacudida durante el medioevo cuando la concepción teocéntrica del mundo desplaza a todo criterio que pretendiera otorgarle al ser humano un lugar más allá del concebido por la interpretación unilateral de las sagradas escrituras.

Una de las supremas expresiones de ese criterio que inculcaba la subordinación del "hombre respecto a Dios" se alcanza en Tomás de Aquino (1975), para quien "en sólo Dios consiste la beatitud del hombre"(p. 426). A su juicio " para el conocimiento de cualquiera verdad necesita el hombre del divino auxilio, de manera que el entendimiento sea movido por Dios a sus actos" (Aquino, 1975, p. 426).

Superar esa concepción empequeñecedora del ser humano sería el largo empeño de la filosofía de los nuevos tiempos. Lograr el retorno del ser humano a sí mismo constituyó la esencia del movimiento renacentista (Abbagnano, 1967, p. 24). Pero sus objetivos parecían ser incluso más ambiciosos, pues se trataba, como plantea Windelband, de otorgarle también un puesto en el cosmos (Windelband, 1943, p. 47) 22 .

20 “ ¡Oh raza de los hombres sin ventura!! ¡Cuando a los dioses concedió existencia y los armó de cólera inflexible, cuántos gemidos asimismo entonces, qué heridas y qué llantos a nuestra descendencia ocasionaron!" Caro, Tito Lucrecio. De la naturaleza de las cosas. Madrid. 1968. p.273.

21 "Lo principal has de saberlo, es tener creencias sólidas pensar que existen y gobiernan el mundo con bondad y con justicia y que te pusieron sobre la tierra para que los obedezcas y para que te doblegues a todo acontecer y lo aceptes de una manera voluntaria..." Epicteto. “Enquiridion. Manual” en Julián Marías. p.206.

22 "De ahí que tome la filosofía natural del Renacimiento, como punto de partida de su problemática, el puesto del hombre en el cosmos, y la metamorfosis de las ideas que se lleva a cabo en este aspecto bajo el influjo de las invenciones y descubrimientos así como del cambiante estado cultural por ellas provocado, llegó a ser decisivo para la nueva imagen de la cabal concepción del mundo." Windelband, Wilhelm. Historia de la Filosofía. Antigua librería Robredo. México. 1943. p.47. 
El reconocimiento de las potencialidades humanas se convirtió en tarea fundamental de los principales humanistas de esa época, que encontraron un paradigma en el mundo grecolatino donde el humano había alcanzado extraordinarios éxitos en la conquista de su condición de Ser por excelencia, al menos en este planeta.

Los logros alcanzados en el desarrollo científico y técnico en ese período expansivo de la historia humana cuando la sociedad burguesa se resistía a seguirse conservando en los estrechos límites de los muros citadinos, posibilitaron cada vez una mejor comprensión del valor de lo humano, aun cuando no haya sido cotizado igualmente en aquellos nacientes países del capitalismo que en las colonias que los amamantarían hasta nuestros días.

A partir de ese momento, el saber humano recobró la dignidad perdida, por cuanto se identificó con las nuevas formas de poder. Las audaces teorías cosmovisivas como las de Copérnico (Morales, 1988, p. 165), ${ }^{23}$ Kepler o Bruno se hicieron peligrosas no solo para las creencias religiosas hasta entonces dominantes, sino también para los intereses socioeconómicos feudales, que se resguardaban ante la ofensiva de las fuerzas sociales emergentes.

La tesis de Francis Bacon (1963) en su Nuevo órgano de que "en el hombre ciencia y poder coinciden en un mismo punto, porque el desconocimiento de la causa hace imposible la obtención del efecto correspondiente" (p. 846), sintetiza la labor que emprendería el ser humano moderno por ocupar paulatinamente niveles superiores de vida y dejar atrás aquellos elementos extraños a su naturaleza emancipadora. El afán por lograr una aceleración en el conocimiento científico que le posibilitara crear mejores condiciones de existencia, y la superación del oscurantismo y la superstición, hacían parecer que se aproximaba el fin de toda alienación humana y el triunfo definitivo del humanismo.

23 "Copérnico y el significado histórico de su obra, en el siglo xvi, nos parece que traduce la dialéctica del poder y el saber en sus interrelaciones y dominios, al ser un símbolo de toda una tradición y contradicción de la mística y de la razón del Renacimiento, traducido como su osadía y su temor a la grandeza y la miseria de la raza humana mediante un mundo que perdía su finitud." Morales García, Elena. "Poder e saber, saber e poder no seculo XVI. Uma análise sobre o caso Copérnico." en Uma história da filosofía. Razáo e mística na ideade media. Universidade Federal do Rio de Janeiro-Universita Universidade aberta. Rio de Janeiro. 1988. p. 165. 
Sin embargo, muy pronto algunos de aquellos titanes del pensamiento que emprendieron esa colosal empresa, indudablemente humanista y desaliendora, se percataron de que, cual pesada rémora, otros factores como la injusta distribución social de la riqueza frenaban el avance hacia el humanismo real.

Los utopistas del Renacimiento fueron los abanderados en denunciar los hasta entonces soslayados ingredientes enajenantes, y que a partir de entonces se irían constituyendo en blanco preferido de los nuevos portavoces del humanismo (Moro, 1956, p. 35). ${ }^{24}$

A partir de entonces, la lucha contra las distintas formas de enajenación traerá aparejada de un modo u otro cada vez en mayor grado la definición ante la problemática socioeconómica. El estudio de las demás formas de alienación no se abandonará, por el contrario, incluso se irán esclareciendo progresivamente con la ilustración, la filosofía clásica alemana, el marxismo y algunas filosofías del pasado siglo xx. Pero precisamente, al irse delimitando el decisivo significado de la enajenación en las relaciones económicas, se fueron haciendo más comprensibles sus múltiples modalidades, especialmente las surgidas en las novedosas condiciones del mundo contemporáneo.

Las ideas humanistas alcanzaron un esplendor extraordinario en la ilustración porque los avances de las ciencias, los retrocesos del oscurantismo y el fanatismo religioso, las conquistas del incipiente desarrollo industrial, el florecimiento de las ciudades, la aparición de legislaciones y de documentos que encontraron consenso universal como La Declaración de los Derechos del Hombre y el Ciudadano, la secularización de la vida y sobre todo del arte, ofrecían a los seres humanos amplias perspectivas de lograr niveles superiores de dominio y de entronizarse como verdaderos señores del mundo con una visión más cosmopolita.

24 Tomás Moro al respecto escribía que: "estimo que dondequiera que exista la propiedad privada y se mida todo por el dinero, será difícil lograr que el Estado obre justa y acertadamente, a no ser que pienses que es obrar con justicia el permitir que lo mejor vaya a parar a manos de los peores, y que se vive felizmente allí donde todo se haya repartido entre unos pocos que, mientras los demás perecen de miseria, disfrutan de la mayor prosperidad." Moro, Tomas, Campanella, Tomas y Francis Bacon Utopías del Renacimiento". Fondo de Cultura Económica. México. 1956. p.35. 
La función humanista de la filosofía tiene como punto de partida la consideración de la capacidad humana para la permanente perfección de sí mismo por encima de las diferencias étnicas y nacionales existentes entre los humanos. Este hecho no ha sido siempre debidamente atendido.

Pero en el caso del jesuita mexicano Pedro José Márquez, quien fuera expulsado de América a mediados del siglo xviII junto a tantos otros, se aprecia la confianza cosmopolita en el ser humano que trata de superar todo tipo de nacionalismo estrecho o incluso racismo cuando sostiene:

De tantas naciones que cubren nuestro globo, no hay una sola que no se crea mejor que las otras, así como no hay cosa más ordinaria entre los habitantes de la tierra que el burlarse uno del otro cuando lo oye hablar un lenguaje que no es el suyo nativo: efecto de ignorancia que se observa aun en muchos que se tiene por doctos y discretos. Pero el verdadero filósofo, así como no siente a tales opiniones, así tampoco acusa inmediatamente de error a todos en un solo haz. Es cosmopolita (o sea ciudadano del mundo) tiene por compatriota a todos los hombres y sabe que cualquier lengua, por exótica que parezca, puede en virtud de la cultura ser tan sabia como la griega, y que cualquier pueblo puede por medio de la educación puede llegar a ser tan culto como el que crea serlo en mayor grado. Con respecto a la cultura la verdadera filosofía no reconoce incapacidad en el hombre, o porque haya nacido blanco o negro, o porque haya sido educado en los polos o en la zona tórrida. Dada la conveniente instrucción -enseña la filosofía-, en todo clima es hombre es capaz de todo (Márquez, 1962, p.133).

Esta es una de las mejores evidencias de la pujante fortaleza humanista y universalizadora en que se fue gestando el más auténtico pensamiento filosófico en América Latina.

Sin embargo, los acechos de nuevas formas de enajenación que ha generado la modernidad, tan malograda en Latinoamérica (Guadarrama, 1998, pp. 134-143) y que podían atentar contra el tan anhelado y cultivado humanismo, ha preocupado a filósofos, artistas, escritores, científicos, y otros; y se plasmarían a través de diversas manifestaciones culturales y desde distintas perspectivas ideológicas. A todas ellas les era común la preocupación por mostrarle al ser humano de los nuevos tiempos, que la modernidad estaba preñada de encantos, pero también de conjuros. Y que las 
próximas batallas, - que por supuesto no se reducirían a simples polémicas teóricas-, como hijo ya adulto de la civilización, debía emprenderlas sin esperar por otros que no fueran sino humanos similares a él, y sin más ni menos poderes extraordinarios para batir los nuevos demonios alienantes que no fueran sus propias y "naturales" fuerzas humanas.

Otras funciones, como la utópica, (Tamayo, 2012, p. 13), ${ }^{25}$ podrían ser propuestas y estudiadas con mayor detalle en el filosofar y de seguro el balance final siempre resultara muy positivo y a favor de que esta forma de saber humano no desaparezca. Pero sería iluso pensar que los filósofos no han dudado también de la utilidad de su actividad. No siempre han confiado en que las energías gastadas en tal empresa intelectual han tenido adecuado eco o plena justificación.

Algunos, al efectuar un análisis de su profesión, se la han cuestionado autocríticamente, como el caso de Voltaire quien planteaba:

No creo que haya existido jamás filósofo que haya propuesto un nuevo sistema, que no haya confesado al final de su vida que haya perdido el tiempo. Hay que confesar que los inventores de las artes mecánicas han sido más útiles a la humanidad que los inventores de los silogismos; el que inventó la lanzadera, fue más útil que el que adivinó las ideas innatas (Voltaire, 1986, p. 239).

No es menos cierto que tales dudas y vacilaciones aparecen en épocas de crisis, como las ocurridos a fines del siglo xx con el derrumbe del "socialismo real" y en tiempos actuales del neoliberalismo real, en la cabeza de algunos que han llegado a consagrar su vida al filosofar, mientras no han hecho de la filosofía más que un simple medio de vida. Hasta aparecen casos en que algunos menos enamorados de la filosofía cortan sus lazos con ella y lanzan sus libros al basurero, donde por extraña suerte, al final, siempre encuentran alguna curiosa mano recolectora.

25 “(...) la rehabilitación crítica de la utopía como invariante de la historia humana, principio presente y actuante en la estructura de la realidad, elemento constitutivo del ser humano, motor de la historia, instancia crítica de la realidad, imagen visualizadora y anticipadora de otra realidad, y horizonte de transformación.” Tamayo, Juan José. Invitación a la utopía. Estudio histórico para tiempos de crisis. Trotta, Madrid. 2012. p. 13. 
Todo parece indicar que el sofisticado mundo tecnológico y del consumo "postmoderno" modificará sustancialmente tantos mecanismos usuales de la cultura, que la filosofía no puede escapar de ellos. Y las nuevas vías informáticas parecen acomodar al atiborrado consumidor, que cree tener cada vez mejores criterios para seleccionar los mejores enlatados, el mejor deporte, el más agradable entretenimiento, y demás, aunque no siempre se percate de no haber hecho la mejor elección. En su permanente pase de cuentas con lo inservible del pasado, el ser humano puede llegar incluso hasta aborrecer todas las filosofías existentes, pero tal vez no se percatará que jamás podrá vivir en un mundo en el que, de un modo u otro, no se practique el ejercicio del filosofar.

A partir de entonces la lucha contra las distintas formas de enajenación traerá aparejada de un modo u otro cada vez en mayor grado la definición ante la problemática socioeconómica. El estudio de las demás formas de alienación no se abandonará, por el contrario, incluso se irán esclareciendo progresivamente con la ilustración, la filosofía clásica alemana, el marxismo y distintas posturas filosóficas del siglo pasado xx como la escuela de Frankfurt y algunos intelectuales latinoamericanos. Pero precisamente, al irse delimitando el decisivo significado de la enajenación en las relaciones económicas e ideológicas, se fueron haciendo más comprensibles sus múltiples modalidades, especialmente las surgidas en las novedosas condiciones del mundo globalizado contemporáneo.

El hecho de que haya sido un tema profusamente investigado no significa en modo alguno que constituya un tema ya agotado, pues nuevas formas de enajenación emergen constantemente y no siempre determinadas por las relaciones capitalistas de producción. También el socialismo en sus distintos ensayos ha engendrado nuevas formas de enajenación. No es que el ser humano por naturaleza sea un ser siempre enajenable, en verdad es un ser histórico que ante las nuevas e históricas formas de enajenación que genera la sociedad es capaz de crear métodos y fórmulas para enfrentarlas y superarlas. 

Capítulo II

BIBLIOTECA

(1E COLOMBIANA 
